\title{
Efficiency of Demand Shocks in Order to Reduce Current Account Imbalances in the EMU
}

\author{
Séverine Menguy \\ Université Paris Descartes, 12 Rue de L'école de Médecine, 75270 Paris Cedex 06, France \\ Correspondence should be addressed to Séverine Menguy; severine.menguy@orange.fr
}

Received 16 August 2013; Accepted 9 September 2013

Academic Editors: J. M. Labeaga and E. Yeldan

Copyright (@ 2013 Séverine Menguy. This is an open access article distributed under the Creative Commons Attribution License, which permits unrestricted use, distribution, and reproduction in any medium, provided the original work is properly cited.

\begin{abstract}
With the current European sovereign public debt crisis and current account imbalances difficulties in the EMU, many papers now underline that the problem of the European construction is its lack of institutional framework and common economic governance necessary to make a monetary union viable. According to these papers, the solution would lie in a stronger economic cooperation, with the Northern European countries contributing to lighten the burden of the Southern debtor countries. In this context, our model shows that a symmetric positive demand shock in the EMU could only slightly reduce the external indebtedness of the Southern European countries but would efficiently reduce their public debt levels. To the contrary, an asymmetric positive demand shock in the creditor Northern European countries (e.g., an increase in German wages) could reduce the current account deficits of the Southern European countries, in particular for countries with the highest openness to trade. Nevertheless, it would worsen the indebtedness levels, and it would also increase the recessionary risks in these countries.
\end{abstract}

\section{Introduction}

In the framework of a monetary union, the member countries loose variations in nominal exchange rates and in interest rates in order to adjust to cyclical economic variations and to stabilize asymmetric shocks. Therefore, real exchange rates can only vary thanks to variations in relative prices. However, at least in the short run, wages and prices are not very flexible. Therefore, budgetary policies must compensate for the price rigidity to allow the adjustment of the output and labor markets. In the absence of any centralized transfer and adjustment mechanism, as in the European Economic and Monetary Union (EMU), the weight of the stabilization can then become too heavy for budgetary policies. So, a growing literature underlines today the problem inherent in the European framework. Monetary unification did not go with a parallel fiscal integration. Thus, an imperfect monetary union without a fiscal union can be at the origin of current account imbalances, which can contribute to accentuate fiscal difficulties and create the conditions of a public debt crisis.

1.1. Current Account Imbalances in the EMU. European authorities mostly blamed the fiscal laxity of some European governments for the financial and sovereign public debt crisis since 2008. Nevertheless, many recent economic papers have also stressed the role of current account imbalances for the current European crisis. Indeed, since the 1970s, Northern European countries have accumulated rising and persistent current account surpluses, while Southern countries have accumulated current account deficits and have seen an appreciation of their real exchange rates, because of rising labor costs. (In conformity with empirical observations, we will consider Germany, Austria, Finland, The Netherlands, and Luxembourg as "Northern" or core European countries, whereas Greece, Ireland (despite its geographical situation), Portugal, and Spain are "Southern" or periphery European countries. Cyprus, Malta, and Slovenia could be added to these Southern countries (see [1]). The situation of France, Italy, and Belgium is more ambiguous: they had current account surpluses in 1999, but they have now current account deficits, even if they remain more moderate.) As mentioned by Schnabl and Wollmershäuser [2], for example, these imbalances remained limited before 1999, but they were accentuated and increased to unprecedented levels after the creation of the EMU. Indeed, Stockhammer [3] underlines, at a worldwide level, the opposition between a model of credit 
financed consumption growth and residential investment in some countries (United States, Spain) and, on the contrary, an export-led growth model in Germany, Japan, China, and other South East Asian countries. In Europe, Uxo et al. [4] underline the fact that two models have emerged. For the Northern countries, their economic growth was led by low wages, strong competitiveness, and low internal growth rates compensated by strong exports. On the other hand, Southern European countries had a growth model based on internal growth of domestic demand financed by external debt. Nevertheless, the authors mention that this bipolar model is detrimental to global demand in the monetary union and unsustainable in the long term.

Southern European countries have a preference for consumption, whereas Northern countries favor sparing and price stability, implying more current account deficits for the Southern countries. Higgins and Klitgaard [5] and Gros [6] underline the problem: foreign capital flows coming for an abundance of sparing in Northern countries were directed towards Southern countries. However, foreign capital was used to finance consumption (because of a weak and decreasing private saving in Greece and Portugal) or boom in the housing market (in Spain and Ireland), rather than to capital investment, and to increase productivity in the Southern countries. Cesaratto [7] and Jaumotte and Sodsriwiboon [1] also mention that foreign capital was mainly used to finance consumption and housing, but not productive investment in the tradable sector. Therefore, Tilford and Whyte [8] underline that the blame for current account imbalances in Europe and for the crisis is also to be put on the Northern countries, whose banks were highly indebted without acutely managing the risk of their investment in Southern countries.

The econometrical study by Arghyrou and Chortareas [9] insists mainly on the importance of higher than average EMU income growth and also on other factors contributing to real exchange rate appreciation (higher relative inflation rates and thus loss of competitiveness) in order to explain growing current account deficits in the Southern European countries after the introduction of the Euro. Giavazzi and Spaventa [10] mention that the appreciation of the real exchange rates of the Southern countries would have been the consequence of a convergence process, if it was accompanied by higher productivity and growth rates and anticipations of higher future growth rates in these countries. However, labor as well as capital productivity soon began to decline in the Southern countries (they have always been low in Portugal). Therefore, the intertemporal condition that current external debt must finance productive investment and allow future commercial surpluses did not seem to hold, as investments were mainly made in the non-traded goods sector like construction, in particular. In these conditions, as symptom of future insolvency problems, the appreciation of the real exchange rate became a source of instability and a self-fulfilling process of divergent evolution.

Fiscal policies then reinforced these external divergences. Indeed, the Southern countries were less competitive, which decreased their exports and implied higher current account deficits, depressing their global demand. Therefore, these external imbalances necessitated higher budgetary deficits, which were at the origin of "twin deficits" in the Southern countries. Besides, as EMU member countries had divergent fiscal paths, with Southern countries becoming more indebted with higher budgetary deficits, capital flows had to be directed towards these countries. However, Northern countries were less and less anxious to provide the necessary financial funds to their spendthrift partners. Indeed, after the credit boom, private capital flows suddenly stopped with the financial crisis, after 2009. Indeed, the current account deficits of the Southern countries were then considered by the financial markets as a sign of weak capacity to repay their public debt. So, there were capital outflows from these countries, increasing their interest rates and accentuating their fiscal difficulties, as mentioned by Canale and Marani [11] and Gros [12], for example. On the contrary, the virtuous Northern countries experienced capital inflows reducing their interest rates and still improving their fiscal situations. But these growing current account imbalances are unsustainable in the long run. De Grauwe and Yuemei [13] mention that in comparison with the United Kingdom or the United States, for example, EMU member countries are more vulnerable to a self-fulfilling financial crisis. Indeed, in such a monetary union, the member countries have no national central bank as lender of last resort guaranteeing that bonds will always be repaid. If investors fear that a country can default on its debt, the rise in interest rates on public bonds can make this prophecy self-fulfilling. Countries which face distrust can suffer a liquidity crisis, capital outflows, more austerity measures, and a recession, whereas countries of which the financial markets trust benefit from capital inflows and improve their budgetary situation.

Canale and Marani [11] assess that fiscal austerity in the Southern countries in order to reduce their budgetary deficits and their indebtedness levels would not be sufficient in order to solve the current European crisis. Indeed, before 2008, the public debt was much smaller in Spain or Ireland, for example, than in Germany. Therefore, the stress is mainly put, today, on the role of current account disequilibria to fuel the European crisis. These imbalances are at the origin of reinforced self-fulfilling behaviors, as the investors are reluctant to lend countries whose external positions are deteriorated, because their loss of competitiveness undermines their potential capacity to repay in the future the loans they have received. In the same way, according to Alessandrini et al. [14], losses of competitiveness, sticky real exchange rates, persistent trade deficits, sudden stops in capital flows, and vanishing liquidity can account for a debt crisis independently of fiscal irresponsibility. Their econometrical model shows the new importance of external imbalances and of the balance of payment crisis to explain the outbidding of interest rate spread for the Southern European countries since 2010. Holinski et al. [15] also mention that the Southern countries have entered in a vicious circle: higher net factor payments and interest rate charges to reimburse their foreign public debt imply an autonomous increase of their public indebtedness towards Northern countries, in which the trade balance plays a more and more insignificant role. It is not the trade balance dynamics that cause current account deficits in 
the Southern countries but rather the loss in their transfer receipts and the increase in their net factor payments.

\subsection{The Remedy of a Positive Demand Shock in Germany.} This consideration of external imbalances is very new in the European institutional framework. Indeed, it was fully absent in the Maastricht Treaty. A new surveillance and enforcement mechanism has been set up in December 2011 as part of the so-called Six-Pack legislation, which reinforced economic governance in the EU and the euro area. However, the problem of the new Macroeconomic Imbalances Procedure (MIP) is that the European Commission put pressure on debtor countries to correct their situation, whereas the situation is not symmetric, as no similar pressure is put on creditor countries to reduce their current account surpluses. Countries at risk of running excessive level of private sector indebtedness and current account deficits would be placed in an "Excessive imbalances position." But countries with surpluses are not clearly compelled to take corrective action [12].

As mentioned by Merler and Pisani-Ferry [16], Southern European countries then face a dilemma. A smaller inflation rate and a relative deflation vis-à-vis Northern countries would be necessary in order to increase their price competitiveness and to reduce their excessive external deficits. However, a sufficiently high inflation rate would allow decreasing the burden of their excessive indebtedness level. So, the solution is to increase the absolute inflation rate in the Southern European countries, while at the same time increasing more than proportionally the inflation rate in the Northern European countries, in order to improve the relative competitiveness of the Southern countries. The global European policy framework must be coherent, and, therefore, the Northern countries must also adjust their economic policies in a way beneficial to all the monetary union member countries. Indeed, with the end of cheap borrowing and external financing, Higgins and Klitgaard [5] underline that there are three available solutions for the Southern European countries.

The first one is to accept an internal devaluation, an increase in their real exchange rates, with a reduction of domestic wages in particular. However, this would probably be costly in terms of economic growth, consumption, and investment spending for the Southern countries. Indeed, Gros [6] estimates that in Greece, for example, labor costs and wages would have to decrease by between $10 \%$ and $20 \%$ in the private sector in order to restore a sufficient price competitiveness. In the same way, De Grauwe [17] underlines that an "internal devaluation," with a relative decrease in wages and prices in the Southern countries, would be very painful for them in terms of depressed economic growth and of growing budgetary deficits. Such an internal devaluation has already begun since 2008 in Ireland, Greece, and Spain; the efforts were much more reduced in Italy and Portugal. Nevertheless, at the same time, no significant internal reevaluation took place in the Northern European countries, which increased the cost of the adjustment for the Southern countries.

The second option is to encourage productivity gains in the Southern countries. However, productivity growth depends on capital investment, education, innovation, product market regulation, labor market flexibility, and the business environment. So, the estimates by Jaumotte and Sodsriwiboon [1] suggest that raising labor productivity and moderating unit labor costs (in particular, minimum wages) could substantially improve the current account positions of the Southern European countries. Nevertheless, adjustments on the labor market and benefiting from the consequences of productive investment are a long term process, which could take much time for the Southern countries. The last option is that the other (in particular Northern) European countries accept increasing their wages and their economic growth, in order to increase their imports and global demand in the monetary union. This would increase net exports of the Southern countries, even if the latter do not improve their competitiveness. This solution seems today the most easily reachable from an economical point of view in Europe, even if it is not the most likely from a political viewpoint. More symmetry in the correction of imbalances in the EMU would certainly lighten the burden of the adjustment for the Southern countries.

Horn et al. [18] underline that the German one-sided orientation towards foreign trade cannot be sustainable. Germany needs a more sustainable growth model more oriented towards the domestic market. Wage increases in Germany would be beneficial to the purchasing power and to global demand and would more than compensate the loss in net exports. Stockhammer [3] also assesses that a redefinition of the European wage policy and an increase in German wages would be beneficial, even if the inflation rate is then higher than the ECB target of $2 \%$. Institutionally, this would require a European coordination system of wage bargaining, which is politically very unlikely to happen in the coming years, but according to the author, these obstacles would have to be overcome in order to solve the current European crisis. The structural domination of the creditor countries is a major failure of the EMU, whereas a symmetric adjustment in the monetary union would reduce the stabilization cost for the Southern European countries and perhaps also the global loss in terms of deflation and economic recession for all the monetary union. Fiscal retrenchment, imposing strong austerity measures in the Southern countries, would accentuate the deflation and depression on the internal demand of these countries, which would also undermine their ability to repay their debts and to stabilize their fiscal situation. Such a context would decrease the exports and could lead to a recession also in the other member countries of the monetary union. On the contrary, according to Uxo et al. [4], Merler and PisaniFerry [16], De Grauwe [17], Canale and Marani [11], and Alessandrini et al. [14], sharing the burden of the adjustment, with a higher inflation rate and an increase in wages in the Northern countries, could be beneficial for all the monetary union member countries. Tilford and Whyte [8] go further; they consider that the European EMU necessitates a real fiscal union, based on fiscal transfers from creditor to debtor countries and on the issuing of Eurobonds. In the context of these recent economic papers, with a simple macroeconomic model, Merler and Pisani-Ferry [16] show that a scenario where the inflation rate increases in the Northern European 
countries, so as to stabilize the average inflation rate in all the monetary union member countries, would be more beneficial than a scenario where the Northern countries only try to stabilize their own inflation rate. Indeed, it would allow the Southern European countries to regain price competitiveness at a smaller cost for their public finances and for the process of reduction of their public debt.

In this framework, the aim of our paper is to study precisely the theoretical implications of symmetric or asymmetric demand shocks, regarding both the external imbalances in the European EMU and the indebtedness problems of the European countries. Indeed, a symmetric demand shock in all the monetary union member countries would be more efficient in order to reduce the indebtedness levels of the Southern European countries; however, current accounts differentials would then hardly be reduced in the EMU. On the contrary, an asymmetric demand shock in the Northern European countries could more efficiently reduce external imbalances in the monetary union. However, it would also increase recessionary risks and public debts in the Southern European countries. Besides, our model shows that the conditions of efficiency of demand shocks also depend on the structural heterogeneity among the member countries of the EMU. The structure of our paper is as follows. Section 2 describes a macroeconomic model able to analyze the consequences of symmetric or asymmetric demand shocks, with structural heterogeneity between the member countries of the monetary union, and also introducing the detention of foreign assets and the preference of the governments for current accounts stabilization. Section 3 studies the relative efficiency of symmetric or asymmetric demand shocks in order to reduce current account imbalances in a monetary union, as well as the costs of the optimal budgetary policies in terms of public debt. Finally, Section 4 concludes the paper.

\section{The Model}

We consider a dynamic New-Keynesian model of a monetary union with two distinct kinds of countries: the "North" (N) and the "South" (S). Each subgroup of country is composed of two sectors, households and firms, and of a fiscal authority. We suppose a closed monetary union vis-à-vis the rest of the world, whose countries face symmetric or asymmetric supply or demand shocks. Besides, we suppose that symmetric and asymmetric components of each shock are independently distributed. Anticipations are rational; each economy produces a single perfectly substitutable good. All variables are expressed in deviations from their long run equilibrium values, and the model is therefore in a log-linearized form. Monetary policy is defined by a central bank common to all the monetary union member countries. Budgetary policies are set by the decentralized governments at the national level. Financial markets are supposed to be perfect, whereas goods markets are characterized by nominal price rigidities.

2.1. Inflation and Economic Activity. We use a stylized dynamic New-Keynesian model, which is broadly consistent with this literature, even if we do not detail here its underlying microeconomic structure (see, e.g., Lieb [19] or Galí and
Monacelli [20] for the microfoundations of the model). The reduced form and linearized demand equation for the zone (i) in period $(t)$ is as follows:

$$
\begin{aligned}
y_{i, t}^{d}= & E_{t}\left(y_{i, t+1}\right)-\sigma_{i}\left[i_{t}-E_{t}\left(\pi_{i, t+1}\right)-\bar{r}\right] \\
& +\eta_{i}\left(\pi_{j, t}-\pi_{i, t}\right)-\left(1-\sigma_{i}\right) E_{t}\left(\Delta g_{i, t+1}\right)+\varepsilon_{i, t}^{d},
\end{aligned}
$$

with, in period $(t)$ for the group $(i)=(\mathrm{N})$ for the "North" or $(\mathrm{S})$ for the "South," $\left(y_{i, t}\right)$ being output or economic activity level; $\left(\pi_{i, t}\right)$ being inflation rate; $\left(g_{i, t}\right)$ being public expenditure; $\left(\varepsilon_{i, t}^{d}\right)$ being positive demand shock, which is a white noise; $\left(i_{t}\right)$ being common nominal interest rate; $\bar{r}$ being real equilibrium interest rate (time discount rate); $E_{t}()$ being rational anticipation operator. $0<\sigma_{i}<1$ : share of private consumption in GDP in the zone $(i)$, in the efficient steadystate, in comparison with the share of public consumption: $\left(1-\sigma_{i}\right) .0<\eta_{i}<1$ : openness to trade of the zone $(i)$.

Traditionally, in New-Keynesian models, aggregate demand is driven by the optimizing behavior of households, which maximize an intertemporal utility function. Thus, output depends on expected future output, because rational agents can maximize their decisions intertemporally and smooth their consumption. Variation in demand is also an increasing function of the variation in public expenditure in a given zone in comparison with what is expected for the following period $\left[g_{i, t}-E_{t}\left(g_{i, t+1}\right)\right]$. It is a decreasing function of the excess of the anticipated real interest rate in the monetary union in comparison with its equilibrium value. Besides, net exports of the zone (i) are an increasing function of its price competitiveness. (In the traditional demand function, net exports depend on prices differentials. But in comparison with the steady state equilibrium, we suppose that a higher inflation rate damages the relative competitiveness of a zone.) Finally, variation in demand is also an increasing function of a national positive demand shock $\left(\varepsilon_{i, t}^{d}\right)$. Moreover, we consider that the structural parameters of this demand function $\left(\sigma_{i}\right.$ and $\left.\eta_{i}\right)$ can vary between the Northern and Southern countries of the monetary union.

The reduced form and linearized supply function is represented by a forward looking New-Keynesian Phillips curve:

$$
\pi_{i, t}=b E_{t}\left(\pi_{i, t+1}\right)+k_{i} y_{i, t}+v_{i} \pi_{j, t}-\varepsilon_{i, t}^{s},
$$

with, in period $(t)$ in the zone $(i),\left(\varepsilon_{i, t}^{s}\right)$ being positive supply, or productivity shock, or negative cost-push shock, which is a white noise. $0<b<1$ : time discount factor (supposed to be identical among the member countries of the monetary union); $0<k_{i}<1 ; 0<v_{i}<1$.

Indeed, in New-Keynesian models, aggregate supply results from the behavior of firms that set prices for their products so as to maximize profits in a monopolistic competition setting. Inflation then depends on expectations about future prices, because of learning effects. Besides, the output gap expresses the demand-pull factor and tensions on the utilization of productive capacities. In this framework, $\left(k_{i}\right)$ is a parameter representing the degree of price flexibility in the zone $(i)$. It is an increasing function of the labor market 
flexibility, of the sensitivity of prices to marginal costs, and of the sensitivity of real wages to the number of workers and to unemployment. On the contrary, more price rigidity in the labor market implies a lower value of $\left(k_{i}\right)$. Prices also increase with imported inflation $\left(v_{i}\right)$. Finally, $\left(\varepsilon_{i, t}^{s}\right)$ captures a deflationary shock unrelated to excess demand (mark-up, etc.). (In this model, we neglect the coefficient relative to the negative effect of the fiscal gap on prices, as this coefficient seems quite low. For example, the calibration of Galí and Monacelli [20] gives a value of $(-0.02)$, Lieb [19] finds $(-0.08)$, and Vogel et al. [21] find (-0.03).)

By combining (1) and (2), we obtain the following prices and economic activity equations (see Appendix A):

$$
\begin{aligned}
& {\left[1+\eta_{i} k_{i}\left(1-v_{j}\right)+\eta_{j} k_{j}\left(1-v_{i}\right)-v_{i} v_{j}\right] \pi_{i, t}} \\
& =-\left[\left(1+\eta_{j} k_{j}\right) \sigma_{i} k_{i}+\sigma_{j} k_{j}\left(k_{i} \eta_{i}+v_{i}\right)\right] \\
& \quad \times \sum_{T=0}^{\infty}\left\{E_{t}\left[i_{t+T}\right]-\bar{r}\right\} \\
& \quad+\left(1+\eta_{j} k_{j}\right) k_{i}\left[\left(1-\sigma_{i}\right) g_{i, t}+\varepsilon_{i, t}^{d}\right] \\
& \quad+k_{j}\left(k_{i} \eta_{i}+v_{i}\right)\left[\left(1-\sigma_{j}\right) g_{j, t}+\varepsilon_{j, t}^{d}\right] \\
& \quad-\left(1+\eta_{j} k_{j}\right) \varepsilon_{i, t}^{s}-\left(k_{i} \eta_{i}+v_{i}\right) \varepsilon_{j, t}^{s} \\
& \quad+f\left[\sum_{T=0}^{\infty} E_{t}\left(y_{i, t+T+1}\right), \sum_{T=0}^{\infty} E_{t}\left(y_{j, t+T+1}\right), \sum_{T=0}^{\infty} E_{t}\left(\pi_{j, t+T+1}\right)\right]
\end{aligned}
$$

$$
\begin{aligned}
& {\left[1+\eta_{i} k_{i}\left(1-v_{j}\right)+\eta_{j} k_{j}\left(1-v_{i}\right)-v_{i} v_{j}\right] y_{i, t}} \\
& =-\left[k_{j}\left(1-v_{i}\right)\left(\sigma_{j} \eta_{i}+\sigma_{i} \eta_{j}\right)+\sigma_{i}\left(1-v_{i} v_{j}\right)\right] \\
& \quad \times \sum_{T=0}^{\infty}\left\{E_{t}\left[i_{t+T}\right]-\bar{r}\right\} \\
& \quad+\left[1-v_{i} v_{j}+\eta_{j} k_{j}\left(1-v_{i}\right)\right]\left[\left(1-\sigma_{i}\right) g_{i, t}+\varepsilon_{i, t}^{d}\right] \\
& \quad+k_{j}\left(1-v_{i}\right) \eta_{i}\left[\left(1-\sigma_{j}\right) g_{j, t}+\varepsilon_{j, t}^{d}\right] \\
& \quad+\eta_{i}\left(1-v_{j}\right) \varepsilon_{i, t}^{s}-\eta_{i}\left(1-v_{i}\right) \varepsilon_{j, t}^{s} \\
& \quad+f\left[\sum_{T=0}^{\infty} E_{t}\left(y_{i, t+T+1}\right), \sum_{T=0}^{\infty} E_{t}\left(y_{j, t+T+1}\right), \sum_{T=0}^{\infty} E_{t}\left(\pi_{j, t+T+1}\right)\right] .
\end{aligned}
$$

Therefore, we find classical characteristics of these economic variables. Prices and economic activity decrease with the interest rate (restrictive monetary policy), and they increase with positive demand shocks. Positive supply shocks reduce prices, but they have ambiguous consequences on economic activity levels. Indeed, they sustain economic growth in the affected zone to the detriment of the rest of the monetary union.
2.2. Current Account and Public Debt. Beyond economic activity and inflation, let us consider two supplementary variables, which are important in the framework of our study. The first one is the current account position. Let us consider that $\left(\mathrm{NFA}_{i, t}\right)$ are net foreign assets in public bonds from the zone $(k)$ owned by the zone $(i)$ in period $(t)$; the interest rate on these public bonds is $\left(j_{k, t}\right)$. Therefore, the evolution of these net foreign assets is

$$
\mathrm{NFA}_{i, t}=\left(1+j_{k, t-1}\right) \mathrm{NFA}_{i, t-1}+X_{i, t} \text {, }
$$

with $X_{i, t}$ : net exports of the zone $(i)$ in period $(t), x_{i, t}$ being net exports in percentage of GDP.

So, in percentage of GDP, we have approximately the following evolution of the net foreign assets position of the zone $(i)$ in period $(t)$ :

$$
\mathrm{nfa}_{i, t}=\frac{\left(1+j_{k, t-1}\right)}{\left(1+y_{i, t}+\pi_{i, t}\right)} \mathrm{nfa}_{i, t-1}+x_{i, t} .
$$

Therefore, the evolution of the current account of the zone (i) in period $(t)$ in percentage of GDP can be measured by the change in its net foreign assets position:

$$
\mathrm{ca}_{i, t}=-\left(y_{i, t}+\pi_{i, t}\right) \mathrm{nfa}_{i, t-1}+\eta_{i}\left(\pi_{j, t}-\pi_{i, t}\right) .
$$

Indeed, the current account of the zone $(i)$ improves if the inflation rate is higher in the other zone $(j)$, which increases the price competitiveness and the net exports of the zone $(i)$. Besides, if the members of the zone $(i)$ are debtor countries vis-à-vis their partners in the monetary union $\left(\mathrm{nfa}_{i, t-1}<0\right)$, higher inflation and real growth rates improve the current account of the zone (i), as they contribute to decrease the value of its external indebtedness in proportion to GDP. On the contrary, if the members of the zone $(i)$ are creditor countries vis-à-vis their partners $\left(\mathrm{nfa}_{i, t-1}>0\right)$, higher inflation and real growth rates deteriorate the current account of the zone (i), as they decrease the value of its foreign assets in proportion to GDP.

Therefore, our model can contribute to explain the current dilemma of the European Economic and Monetary Union. The "Southern countries" accumulated growing external indebtedness positions $\left(\mathrm{nfa}_{s, t-1}<0\right)$, which were sustainable as long as their nominal growth rates were sufficiently high. However, as economic growth strongly fell in these countries, the worsening of their current account positions could not be avoided. Indeed, a weak economic growth and a weak price competitiveness accentuate the current account deficits and external imbalances of these countries. On the contrary, the creditor "Northern countries" of the EMU $\left(\right.$ nfa $\left._{n, t-1}>0\right)$ tend to accumulate current account surpluses. Indeed, a weaker inflation rate improves their price competitiveness, whereas their net foreign asset positions grow.

The last indicator that we will consider in this paper is the indebtedness level of the member countries of the zone $(i)$. The real value of the public debt in the zone $(i)$ increases with the charges on the previously accumulated public debt. So, it increases with the nominal interest rate charges at the rate $\left(j_{i, t-1}\right)$ on government bonds defined in the former period, 
and it decreases with the nominal growth rate in the zone (i): $\left(y_{i, t}+\pi_{i, t}\right)$. Therefore, the evolution of the public debt of the zone $(i)$ in period $(t)$ in percentage of GDP is

$$
D_{i, t}=\frac{\left(1+j_{i, t-1}\right)}{\left(1+y_{i, t}+\pi_{i, t}\right)} D_{i, t-1}+\operatorname{Def}_{i, t} .
$$

With, for the zone $(i)$ in period $(t),\left(D_{i, t}\right)$ being nominal public debt in percentage of GDP; $\left(d_{i, t}\right)$ being variation from baseline; $\left(\right.$ Def $\left._{i, t}\right)$ being primary budgetary deficit in percentage of GDP; $\left(\operatorname{def}_{i, t}\right)$ being variation from baseline; $\left(j_{i, t}\right)$ being nominal interest rate on government bonds; and $\left(t_{i}\right)$ being taxation rate.

So, the evolution of the public debt in terms of deviation from equilibrium value can be given by the following equation:

$$
d_{i, t}=-\left(y_{i, t}+\pi_{i, t}\right) D_{i, t-1}+\operatorname{def}_{i, t} .
$$

Moreover, if we consider that the budgetary deficit is the differential between the budgetary expenditure and resources $\left(\operatorname{def}_{i, t}=g_{i, t}-t_{i} y_{i, t}\right)$, we obtain the following equation for the deviation of the public debt from its equilibrium value:

$$
d_{i, t}=-\left(t_{i}+D_{i, t-1}\right) y_{i, t}-D_{i, t-1} \pi_{i, t}+g_{i, t}
$$

2.3. Loss Functions of the Economic Authorities. We can now turn to the preferences and loss functions of the economic authorities. We suppose that economic policies are endogenous and are the result of a strategic game (Nash equilibrium) between the economic authorities. The preferences of the common central bank are given by the following intertemporal loss function:

$$
L_{t}^{M}=\frac{1}{2} E_{t}\left\{\sum_{T=0}^{\infty} \delta^{T}\left[\alpha_{\pi}^{M} \pi_{t+T}^{2}+y_{t+T}^{2}+\alpha_{i}^{M}\left(i_{t+T}-i_{t+T-1}\right)^{2}\right]\right\},
$$

where the parameters $\left(\alpha_{\pi}^{M}\right)$ and $\left(\alpha_{\pi}^{G}\right)$ express the weights of the price stability goal, the parameters $\left(\alpha_{i}^{M}\right)$ and $\left(\alpha_{g}^{G}\right)$ express the weights of instrument smoothing, the parameter $\left(\alpha_{\mathrm{ca}}^{G}\right)$ expresses the weight of current account stabilization, relative to the output goal normalized to unity, respectively, for the central bank and for the governments, and $(\delta<1)$ is the discount rate of the future.

Indeed, the central bank stabilizes mostly average inflation but also average output in the monetary union as a whole. Besides, we also suppose that price stability is more important for the central bank than for national governments $\left(\alpha_{\pi}^{M}>\alpha_{\pi}^{G}\right)$. Furthermore, the minimization of fluctuations in interest rates is usually justified by the empirical smoothing of interest rates conducted by central banks and by the necessity to avoid large fluctuations which could be damageable for the stability of financial markets.
The preferences of the governments of the zone (i) in period $(t)$ are given by the following intertemporal loss function:

$$
\begin{aligned}
& L_{i, t}^{G} \\
& =\frac{1}{2} E_{t}\left\{\sum_{T=0}^{\infty} \delta^{T}\left[\alpha_{\pi}^{G} \pi_{i, t+T}^{2}+y_{i, t+T}^{2}+\alpha_{g}^{G} g_{i, t+T}^{2}+\alpha_{\mathrm{ca}}^{G} \mathrm{ca}_{i, t+T}^{2}\right]\right\} .
\end{aligned}
$$

The governments of the zone ( $i$ ) stabilize cyclical fluctuations in their zone. However, in order to simplify the model, we suppose that the preferences of the governments of the various countries of the monetary union are identical. As for the central bank, welfare losses increase with the deviation of inflation and output from their targets. For convenience, the inflation target can be set equal to zero, in conformity with the price stability goal. In the same way, the activity target is supposed to be null. Indeed, the targeted level of output is supposed to be given by potential output and is not the choice of the governments; in this paper, there is no "inflation bias" of budgetary policies. Furthermore, the governments' losses also increase with variations in budgetary expenditures. The minimization of fluctuations in public expenditure can be justified by the political pressure on governments to continue fundamental expenditures and to provide some level of public services. It can also be justified by the empirical delays by which these expenditures can effectively be modified and for the implementation of fiscal measures, as well as by the desire to avoid an increase in public debts. Finally, the main contribution of our paper is also to suppose that the governments can take into account current accounts stabilization, in order to consider the present European sovereign public debt crisis also related to current account imbalances. However, contrary to Merler and Pisani-Ferry [16], we consider that the governments of the Southern European countries do not assign automatically their fiscal policies to the goal of competitiveness. They must arbitrate between competitiveness (which corresponds to smaller public expenditure, economic activity, and prices) and reducing their indebtedness levels thanks to higher economic growth and inflation.

2.4. Calibration. In order to calibrate our model, we will retain the following values for our structural parameters.

(i) Share of private consumption in GDP $(\sigma)$ : Galí and Monacelli [20] and Lieb [19] consider a high value for this parameter: $\sigma=0.75$. Vogel et al. [21] suppose $\sigma=$ 0.73 . This is in conformity with the values reported in Table 1. Therefore, we will take the following value for this parameter: $\sigma=0.75$.

(ii) Openness to trade: $(\eta)$ : Galí and Monacelli [20] and Lieb [19] consider a moderate openness: $\eta=0.3$. On the contrary, Vogel et al. [21] suppose a much higher value for this parameter: $\eta=0.73$. In fact, the situation of the European countries is very heterogeneous regarding this criterion (see Table 1). Thus, we will take an intermediary value for this parameter: $\eta=0.5$. 
TABLE 1: Share of private consumption, openness to trade, indebtedness level, and net foreign assets position of some EMU countries.

\begin{tabular}{lcccc}
\hline & Private consumption/GDP (1) & Openness to trade (2) & Public debt/GDP & Net foreign assets/GDP (3) \\
\hline EMU 17 & $\mathbf{7 8 . 5 \%}$ & $\mathbf{4 4 . 3}$ & $\mathbf{9 2 . 7 \%}$ & $\mathbf{2 . 0 \%}$ \\
Austria & $81.0 \%$ & $55.6 \%$ & $73.4 \%$ & $2.9 \%$ \\
Belgium & $75.1 \%$ & $84.2 \%$ & $99.6 \%$ & $0.8 \%$ \\
Finland & $74.9 \%$ & $41.0 \%$ & $53.0 \%$ & $-1.5 \%$ \\
France & $75.3 \%$ & $28.6 \%$ & $90.2 \%$ & $-1.7 \%$ \\
Germany & $80.5 \%$ & $48.8 \%$ & $81.9 \%$ & $6.3 \%$ \\
Greece & $82.2 \%$ & $29.5 \%$ & $156.9 \%$ & $-2.9 \%$ \\
Ireland & $82.5 \%$ & $96.0 \%$ & $117.6 \%$ & $3.7 \%$ \\
Italy & $79.9 \%$ & $29.7 \%$ & $127.0 \%$ & $-0.4 \%$ \\
The Netherlands & $71.5 \%$ & $83.8 \%$ & $71.2 \%$ & $8.0 \%$ \\
Portugal & $81.7 \%$ & $39.1 \%$ & $123.6 \%$ & $0.4 \%$ \\
Spain & $79.9 \%$ & $31.7 \%$ & $84.2 \%$ & $-0.2 \%$ \\
\hline
\end{tabular}

Source: Eurostat.

(1) 1 - (Final consumption expenditure of general government/GDP), in 2012.

(2) (Exportations + Importations of goods and services)/(2* GDP), in 2012.

(3) Net borrowing (-) or net lending (+), total economy, in \% of GDP, in 2012

(iii) Price flexibility $(k)$ : Vogel et al. [21] $k=0.26$; Galí and Monacelli [20] $k=0.24$, and Lieb [19] $k=0.4$ consider the same order of height for price flexibility in Europe. Thus, we will take $k=0.25$.

(iv) Imported inflation $(v)$ : Lieb [19] considers $v=0.3$.

(v) Time discount factor ( $b$ or $\delta$ ): Vogel et al. [21], Galí and Monacelli [20], and Lieb [19] all consider a high discount factor: $b=0.99$

(vi) Debt level in proportion to GDP $\left(D_{t-1}\right)$ : the European countries are very heterogeneous regarding their indebtedness levels (see Table 1). We will take a moderate reference value corresponding to the threshold of the Maastricht Treaty: $D_{t-1}=0.6$.

(vii) Taxation rates $(t)$ : we will take a value corresponding to average taxation rates in the European Economic and Monetary Union: $t=0.4$.

(viii) Net foreign assets $\left(\mathrm{nfa}_{t-1}\right)$ : we will consider that they are null on average, as they are usually positive for Northern European countries and negative for Southern European countries (see Table 1).

(ix) Share of the Northern countries in total GDP of the monetary union $(m)$ : like in Merler and Pisani-Ferry [16], we will take: $m=0.65$.

Finally, regarding the preferences of the economic authorities, we will suppose: $\alpha_{\pi}^{M}=2$ and $\alpha_{i}^{M}=0.5$, as the main goal of the European Central Bank is to preserve price stability. For the governments, $\alpha_{\pi}^{G}=0.2$, and $\alpha_{g}^{G}=0.5$, as governments mainly aim at stabilizing economic variables, but as there are costs of fiscal policy intervention, $\alpha_{\mathrm{ca}}^{G}=0.5$ as the budgetary authorities try to stabilize current account imbalances.

\section{The Implications of Demand Shocks}

We can now define the Nash equilibrium of our model. By combining (3) to (12), we obtain the optimal monetary and budgetary policies conducted by the economic authorities: $\left(i_{t}\right)$ and $\left(g_{i, t}\right)$. Afterwards, we can obtain the optimal variations in prices and economic activity levels as well as in current accounts in the monetary union according to symmetric or asymmetric demand or supply shocks (see Appendix B). However, we will only be interested in this paper in the implications of symmetric or asymmetric demand shocks.

3.1. Effects of Symmetric Demand Shocks. Let us first study the implications of a symmetric demand shock: $\varepsilon_{t}^{d}=\left(\varepsilon_{i, t}^{d}+\varepsilon_{j, t}^{d}\right) / 2$.

After a positive symmetric demand shock $\left(\varepsilon_{t}^{d}>0\right)$, monetary policy is more restrictive (increase in interest rates), as well as the budgetary policies: decrease in budgetary expenditure, budgetary deficit, and public debt, in order to compensate for the expansionary consequences of the shock. For example, with the basic calibration of our model mentioned in Section 2.4, we have $\left(i_{t}=0.48 \varepsilon_{t}^{d}\right)$ and $\left(g_{n, t}=\right.$ $g_{s, t}=-0.26 \varepsilon_{t}^{d}$ ). Obviously, according to (B.3) and (B.4) and to our simulations (numerical simulations are made with EXCEL), we also find that economic policies are complementary in the stabilization of demand shocks and that the respective weights of the economic authorities in the stabilization of these shocks can vary. The budgetary authorities have the strongest weight in the stabilization burden (strong decrease in budgetary expenditure but small increase in interest rates) if the central bank is hardly constrained $\left(\alpha_{i}^{M}\right.$ and $\alpha_{\pi}^{G}$ are high, whereas $\alpha_{\pi}^{M}$ and $\alpha_{g}^{G}$ are small). On the contrary, the stabilization effort of the central bank is the highest (strong increase in interest rates) if the governments are hardly constrained in the variation of their budgetary expenditures ( $\alpha_{\pi}^{M}$ and $\alpha_{g}^{G}$ are high, whereas $\alpha_{i}^{M}$ and $\alpha_{\pi}^{G}$ are small). Nevertheless, in case of symmetric demand shocks, the respective stabilization efforts of the economic authorities do not seem to depend on the importance of external imbalances and on the weight of stabilizing current accounts $\left(\alpha_{\mathrm{ca}}^{G}\right)$ for the governments, according to our model. 
Besides, according to (B.5), (B.6), and (B.7) in Appendix B, in case of structural homogeneity among the member countries of the monetary union, we have

$$
\begin{gathered}
\frac{\partial y_{i, t}}{\partial \varepsilon_{t}^{d}}=\alpha_{g}^{G} \frac{m_{21, i}}{m_{10}} \longrightarrow \frac{(1+2 \eta k) \alpha_{g}^{G}(1+\delta) \alpha_{i}^{M}}{m_{11}} \\
m_{11}=(1+2 \eta k) \alpha_{g}^{G}\left[(1+\delta) \alpha_{i}^{M}+\left(1+\alpha_{\pi}^{M} k^{2}\right) \sigma^{2}\right] \\
+(1+\delta) \alpha_{i}^{M}\left(1+\alpha_{\pi}^{G} k^{2}\right)(1-\sigma)^{2}(1+\eta k), \\
\frac{\partial \pi_{i, t}}{\partial \varepsilon_{t}^{d}}=\alpha_{g}^{G} \frac{m_{19, i}}{m_{10}} \longrightarrow k \frac{\partial \pi_{i, t}}{\partial \varepsilon_{t}^{d}} \\
\frac{\partial \mathrm{ca}_{i, t}}{\partial \varepsilon_{t}^{d}}=\alpha_{g}^{G} \frac{m_{23, i}}{m_{10}} \longrightarrow 0
\end{gathered}
$$

Therefore, prices, economic activity levels, or current accounts could perfectly be stabilized in all countries if there was no constraint on the use of the budgetary instrument $\left(\alpha_{g}^{G}=0\right)$. However, as budgetary authorities are constrained in the use of their budgetary expenditure $\left(\alpha_{g}^{G}>0\right)$, prices and economic activity levels increase in both countries $\left(m_{19}>0\right.$ and $m_{21}>0$ in Appendix B), and all the more as this constraint is heavy. For example, with the basic calibration of our model, we obtain $\left(p_{t}=0.14 \varepsilon_{t}^{d}\right)$ and $\left(y_{t}=0.57 \varepsilon_{t}^{d}\right)$. Economic variables could also be perfectly stabilized if there was no constraint for the central bank on the variation of its interest rate $\left(\alpha_{i}^{M}=0\right)$, provided there is structural homogeneity in the transmission parameters of monetary policy in the monetary union $\left(\sigma_{i}=\sigma_{j}\right)$. Indeed, the restrictive monetary policy would then have the same recessionary consequences on both zones of the monetary union. Otherwise, even if the monetary authority is not constrained $\left(\alpha_{i}^{M}=0\right)$, there are expansionary tensions in the zone (i) which has the smallest sensitivity of its economic activity to the common interest rate $\left(\sigma_{i}<\sigma_{j}\right)$. Indeed, the more restrictive monetary policy has then more recessionary consequences on the zone $(j)$ than on the zone (i), whose economic activity and prices increase. Besides, the expansionary tensions in both zones of the monetary union tend to decrease with the relative weight of stabilizing prices for the economic authorities $\left(\alpha_{\pi}^{G}\right.$ and $\left.\alpha_{\pi}^{M}\right)$, whereas they are more accentuated if stabilization is more imperfect because the economic authorities are more strongly constrained ( $\alpha_{i}^{M}$ and $\alpha_{g}^{G}$ are high).

However, the expansionary tensions and variations in the current accounts do not depend on the importance of external imbalances and on the weight of stabilizing current accounts $\left(\alpha_{\mathrm{ca}}^{G}\right)$ for the governments, according to our model, at least in case of structural homogeneity among the member countries of the monetary union. Besides, the previously accumulated foreign assets have only minor consequences on inflation and economic activity levels, provided $\left(\alpha_{i}^{M} \alpha_{\text {ca }}^{G}\right)$ is nonnegligible. Indeed, according to (13), we have:

$$
\begin{gathered}
\frac{\partial\left(\partial \pi_{i, t} / \partial \varepsilon_{t}^{d}\right)}{\partial \alpha_{\mathrm{ca}}^{G}} \longrightarrow 0, \\
\frac{\partial\left(\partial y_{i, t} / \partial \varepsilon_{t}^{d}\right)}{\partial \alpha_{\mathrm{ca}}^{G}} \longrightarrow 0, \\
\frac{\partial\left(\partial \mathrm{ca}_{i, t} / \partial \varepsilon_{t}^{d}\right)}{\partial \alpha_{\mathrm{ca}}^{G}} \longrightarrow 0 .
\end{gathered}
$$

Therefore, the first results of our model would tend to show that, in case of structural homogeneity, a symmetric expansionary demand shock in all European countries could not be useful in order to solve the problem of external imbalances and of deficits in the current accounts of the Southern European countries. Indeed, as economic activity and prices would tend to grow in parallel in all countries, the insufficient price competitiveness of the Southern European countries would remain unchanged. Nevertheless, our model can provide some supplementary teachings regarding symmetric demand shocks, in case of structural heterogeneity among the member countries of a monetary union.

3.2. Structural Heterogeneity and Symmetric Demand Shocks. Regarding variations in current accounts, the common central bank could perfectly stabilize them if it was not constrained in the variations of its interest rate $\left(\alpha_{i}^{M}=0\right)$, provided the transmission parameters of monetary policy are symmetric in the monetary union $\left(\sigma_{i}=\sigma_{j}\right)$. Indeed, the effects of symmetric demand shocks on prices and activity levels could then perfectly be stabilized in both countries, without effects on current accounts according to (B.7) in Appendix B. However, if the monetary authority is constrained, monetary policy is not enough recessionary, and there remain expansionary tensions in both countries. In these conditions, the Northern countries which have accumulated foreign assets have deteriorated current accounts, as their assets lose some value because of the inflationary tensions. Besides, if the restrictive monetary policy has more limited recessionary consequences on a zone $(i)\left(\sigma_{i}<\sigma_{j}\right)$, growth and inflation are higher in this zone, which reduces net exports and deteriorates current accounts in this zone, provided the size of the two zones is not too distinct.

We can also mention that if price flexibility $\left(k_{j}\right)$ and imported inflation $\left(v_{j}\right)$ are weak in a zone $(j)$ of the monetary union, and all the more as the structural heterogeneity is strong and as these parameters are smaller than in the other zone $(i)\left(k_{i}>k_{j}\right.$ and $\left.v_{i}>v_{j}\right)$, a symmetric positive demand shock reduces the inflationary tensions but increases the expansionary tensions in this zone $(j)$. Therefore, budgetary policy can be more restrictive in the zone $(j)$ in order to stabilize economic growth. Besides, because of the weakest inflation in the zone $(j)$, net exports are higher, which improves the current account of the zone $(j)$ but deteriorates the current account of the zone $(i)$ in the monetary union. Thus, we can mention that external imbalances in a monetary 
union are more easily reduced by a symmetric demand shock if the debtor countries, whose current accounts must be improved, are those with the weakest price flexibility $(k)$ and imported inflation $(v)$. Besides, in these conditions, a positive symmetric demand shock can allow a stronger decrease in the budgetary deficit and can then be a more efficient solution to the debt problem of these countries.

Furthermore, in case of structural homogeneity in the demand and supply functions among the member countries of the monetary union, variations in current accounts only depend on the previously accumulated foreign assets ( $\mathrm{nfa}_{n, t-1}$ and $\left.\mathrm{nfa}_{s, t-1}\right)$, according to the value of $\left(m_{23, i}\right)$ in Appendix B. Besides, as long as the economic authorities are constrained in the use of their instruments $\left(\alpha_{i}^{M} \alpha_{g}^{G}>0\right)$, the foreign assets that the zone $(i)$ has accumulated $\left(\mathrm{nfa}_{i, t-1}\right)$ deteriorate its current account, according to the value of $\left(m_{23, i}\right)$. Indeed, we have

$$
\frac{\partial\left[\partial \mathrm{ca}_{i, t} / \partial \varepsilon_{t}^{d}\right]}{\partial \mathrm{nfa}_{i, t-1}}<0 .
$$

For example, with the basic calibration of our model, if foreign assets represent 6\% of GDP of the Northern zone $\left(\mathrm{nfa}_{n, t-1}=0.06\right)$, its current account would already be deteriorated as follows: $\left(\mathrm{ca}_{n, t}=-0.04 \varepsilon_{t}^{d}\right)$. Indeed, a symmetric positive demand shock creating expansionary tensions in the monetary zone would reduce the value of the foreign assets accumulated by the Northern countries in proportion to their GDP. On the contrary, the expansionary and inflationary tensions would reduce the weight of the foreign indebtedness of the Southern countries $\left(\mathrm{nfa}_{s, t-1}=-0.06\right.$ and $\left.\mathrm{ca}_{s, t}=0.04 \varepsilon_{t}^{d}\right)$. Besides, variations in current accounts would be all the more accentuated as the monetary authority is highly constrained, as $\left(\alpha_{i}^{M}\right)$ is high whereas $\left(\alpha_{\pi}^{M}\right)$ is small. Indeed, the monetary authority stabilizes average variables in the monetary union. Therefore, in order to stabilize country-specific current accounts, it is better if the stabilization effort relies mainly on the governments in the monetary union.

In this framework, according to our model, even a symmetric positive demand shock could contribute to reduce the external imbalances in the EMU. Indeed, it would automatically reduce the value of the current account surpluses of the creditor Northern European countries, whereas it would also reduce the current account deficits of the debtor Southern European countries. Moreover, a positive symmetric demand shock could reduce budgetary deficits and indebtedness levels in the Southern European countries, and all the more as price flexibility and imported inflation are weak in these countries. Nevertheless, our simulations show that the size of the variations in current accounts would remain quite limited in case of a positive symmetric demand shock. Our model also shows the limits of joint and parallel austerity measures in all EMU member countries, which could tend to accentuate external imbalances and debt problems in all the monetary union member countries.

3.3. Effects of Asymmetric Demand Shocks. Now, let us study the implications of an asymmetric demand shock increasing demand in the zone $(i)$ to the detriment of the zone $(j): \overline{\varepsilon_{t}^{d}}=$ $\left(\varepsilon_{i, t}^{d}-\varepsilon_{j, t}^{d}\right) / 2$.

After an asymmetric demand shock, monetary policy would not vary in case of structural homogeneity between the member countries of the monetary union and if they had the same size $(m=0.5)$. Indeed, the monetary authority cannot stabilize asymmetric shocks, which can only be stabilized by national governments. Nevertheless, monetary policy should be slightly restrictive in order to compensate for a positive demand shock affecting the biggest zone of the monetary union ( $m>0.5)$. Besides, according to (B.4) in Appendix B, the budgetary policy is more restrictive in the zone $(i)$ affected by an asymmetric positive demand shock: decrease in budgetary expenditure, budgetary deficit, and public debt. Indeed, with the basic calibration of our model in Section 2.4, we have $\left(g_{i, t}=-0.36 \overline{\varepsilon_{t}^{d}}\right)$. On the contrary, the budgetary policy is more expansionary in the zone $(j)$ affected by a negative asymmetric demand shock: increase in budgetary deficit and in public debt. These results do not depend on the preferences of the monetary authority. However, the budgetary activism is accentuated if the budgetary authorities are less constrained ( $\alpha_{g}^{G}$ is small, $\alpha_{\pi}^{G}$ and $\alpha_{\mathrm{ca}}^{G}$ are high).

Besides, according to (B.5), (B.6), and (B.7) in Appendix $\mathrm{B}$, in case of structural homogeneity among the member countries of the monetary union, we have:

$$
\begin{gathered}
\frac{\partial y_{i, t}}{\partial \varepsilon_{t}^{d}}=\alpha_{g}^{G} \frac{m_{22, i}}{m_{10}} \longrightarrow \frac{\alpha_{g}^{G}(1+2 k \eta)}{m_{12}}, \\
m_{12}=\alpha_{g}^{G}(1+2 k \eta)^{2} \\
+(1-\sigma)^{2}\left[\left(1+\alpha_{\pi}^{G} k^{2}\right)(1+k \eta)+2 \alpha_{c a}^{G} k^{2} \eta^{2}\right], \\
\frac{\partial \pi_{i, t}}{\partial \overline{\varepsilon_{t}^{d}}}=\alpha_{g}^{G} \frac{m_{20, i}}{m_{10}} \longrightarrow \frac{k \alpha_{g}^{G}(1+2 k \eta)}{m_{12}}, \\
\frac{\partial \mathrm{ca}_{i, t}}{\partial \overline{\varepsilon_{t}^{d}}}=\alpha_{g}^{G} \frac{m_{24, i}}{m_{10}} \longrightarrow-\frac{2 \alpha_{g}^{G}(1+2 k \eta) k \eta}{m_{12}} .
\end{gathered}
$$

Therefore, prices, economic activity levels, or current accounts could perfectly be stabilized in all countries if there was no constraint on the use of the budgetary instrument $\left(\alpha_{g}^{G}=0\right)$. However, as budgetary authorities are constrained in the use of their budgetary expenditure $\left(\alpha_{g}^{G}>0\right)$, prices and economic activity levels increase in the zone ( $i$ ) affected by a positive demand shock, whereas they decrease in the zone $(j)$ affected by a negative demand shock $\left(m_{20}>0\right.$ and $m_{22}>0$ in Appendix B), and all the more as this constraint is heavy. For example, with the basic calibration of our model, we obtain $\left(p_{i, t}=0.15 \overline{\varepsilon_{t}^{d}}\right)$ and $\left(y_{i, t}=0.76 \overline{\varepsilon_{t}^{d}}\right)$.

In these conditions, the weaker price competitiveness and growing net imports create a current account deficit in the zone $(i)$, according to $\left(m_{24, i}<0\right)$ in Appendix B, whereas net exports tend to create a current account surplus in the zone $(j)$. For example, with the basic calibration of our model, even in the absence of net foreign assets formerly 
accumulated, we have $\left(\mathrm{ca}_{i, t}=-0.15 \overline{\varepsilon_{t}^{\bar{d}}}\right)$. At least in case of structural homogeneity among the member countries of the monetary union, these disequilibria do not depend on $\left(\alpha_{\pi}^{M}\right)$ and $\left(\alpha_{i}^{M}\right)$, as the monetary authority cannot stabilize asymmetric shocks. However, they tend to decrease with the budgetary activism and the preference of the governments for prices or current accounts stabilization ( $\alpha_{\mathrm{ca}}^{G}$ and $\alpha_{\pi}^{G}$ are high).

Therefore, our model would tend to show that, even in case of structural homogeneity among the member countries of the EMU, an asymmetric positive demand shock in the Northern European countries could contribute to limit external imbalances and deficits in the current accounts of the Southern European countries. Indeed, such a shock would create inflationary tensions and reduce the price competitiveness of the Northern countries, as well as their current account surpluses. Thus, it would reduce external imbalances and current account deficits in the Southern countries, which would benefit from a relatively smaller inflation rate and from a better price competitiveness in comparison with their Northern partners. Nevertheless, an asymmetric negative demand shock would increase budgetary deficits and public debts, and it would create recessionary tensions in the Southern European countries. Furthermore, our model can provide some supplementary teachings regarding asymmetric demand shocks, in case of structural heterogeneity among the member countries of a monetary union.

\subsection{Structural Heterogeneity and Asymmetric Demand} Shocks. First, in case of an asymmetric demand shock, if the monetary policy transmission parameters are weaker in the zone $(i)$ positively affected by the shock $\left(\sigma_{i}<\sigma_{j}\right)$, monetary policy becomes expansionary (decrease in interest rates), because it is more efficient in the zone $(j)$ negatively affected by the shock. The budgetary expenditure is then still weaker and the budgetary surplus is higher in the positively affected zone (i), which reduces the expansionary and inflationary tensions in this zone. The disequilibria are thus slightly more limited between the two zones, slightly reducing current account deficits in the zone $(i)$ and current account surpluses in the partner zone $(j)$. Nevertheless, in such a structural configuration, an asymmetric demand shock would reduce external imbalances at a much smaller cost for the budgetary deficits and the indebtedness levels of the member countries of the zone $(j)$.

Regarding openness to trade, if openness of the zone (i) positively affected by the demand shock is weak and smaller than in the partner zone $(j)\left(\eta_{i}\right.$ is small and $\left.\eta_{i}<\eta_{j}\right)$, this zone (i) must compensate the insufficiently recessionary effect of growing net imports by a higher budgetary activism and decrease in budgetary expenditure. However, it does not avoid the higher inflationary and expansionary tensions in the zone (i). Therefore, the current account can be well improved in the partner zone $(j)$ and at a smaller cost in terms of public indebtedness. On the contrary, if the zone $(i)$ positively affected by the shock is relatively more open $\left(\eta_{i}>\eta_{j}\right)$, its budgetary activism and economic growth are more limited, and its current account surplus is strongly reduced, whereas the shock only slightly improves the external situation of the partner zone $(j)$, with higher risks of outbidding of its public debt level. We can also mention that higher price flexibility in the monetary union $\left(k_{i}\right.$ and $k_{j}$ are high) necessitates weaker budgetary activism and it increases variations in prices but reduces those in economic activity levels. Therefore, differentials in price competitiveness and variations in current accounts are higher and at a smaller cost for the budgetary instrument.

Furthermore, the previously accumulated foreign assets have only minor consequences on inflation and economic activity levels, according to our model. Even in case of structural homogeneity in the demand and supply functions among the member countries of the monetary union, accumulated foreign assets ( $\mathrm{nfa}_{n, t-1}$ and $\mathrm{nfa}_{s, t-1}$ ) mainly influence variations in current accounts, according to the value of $\left(m_{24, i}\right)$ in Appendix B, as soon as the economic authorities are constrained in the use of their instruments $\left(\alpha_{i}^{M}>0\right.$ or $\alpha_{g}^{G}>$ $0)$. More precisely, the foreign assets accumulated $\left(\mathrm{nfa}_{i, t-1}\right)$ by a zone ( $i$ ) affected by an asymmetric positive demand shock deteriorate its current account, according to the value of $\left(m_{24, i}\right)$. Indeed, we have

$$
\frac{\partial\left[\partial \mathrm{ca}_{i, t} / \partial \overline{\varepsilon_{t}^{d}}\right]}{\partial \mathrm{nfa}_{i, t-1}}<0 .
$$

For example, with the basic calibration of our model, if foreign assets represent $6 \%$ of GDP of the Northern zone $\left(\mathrm{nfa}_{n, t-1}=0.06\right)$, its current account would be deteriorated as follows: $\left(\mathrm{ca}_{n, t}=-0.20 \overline{\varepsilon_{t}^{d}}\right)$. Indeed, a positive asymmetric demand shock creating expansionary tensions in the Northern countries would reduce the value of the foreign assets accumulated by these countries in proportion to their GDP. This would be quite independent of the foreign assets accumulated by Southern countries, for which a foreign indebtedness $\left(\mathrm{nfa}_{s, t-1}=-0.06\right)$ would imply a current account surplus $\left(\mathrm{ca}_{s, t}=0.09 \overline{\varepsilon_{t}^{d}}\right)$, according to our basic calibration.

In conclusion, in case of asymmetric demand shocks, in order to reduce external imbalances in the monetary union, it is obviously necessary that the shock positively affects the creditor countries in the monetary union. In this framework, according to our model, an asymmetric positive demand shock affecting the creditor Northern countries of the EMU could reduce external imbalances in the monetary union. Indeed, such a shock would reduce the current account surpluses of the creditor Northern European countries, whereas it would also reduce the current account deficits of the debtor Southern European countries. In order to reduce the current account deficits of these debtor countries at a smaller cost for their indebtedness levels, it would also be better if the debtor countries negatively affected had stronger monetary policy transmission parameters $(\sigma)$. It would also be better if the asymmetric demand shock negatively affects the countries which have the highest openness to trade $(\eta)$ and if price flexibility $(k)$ was high in the monetary union. 


\section{Conclusion}

With the current European sovereign public debt crisis and current account imbalances difficulties in the EMU, many papers now underline that the problem of the European construction is its lack of institutional framework and common economic governance necessary to make a monetary union viable. For example, Tilford and Whyte [8] mention that rigid rules and increasing the austerity in the Southern European countries are not the solution. What would be necessary is a real economic cooperation, in particular, with the Northern European countries contributing to lighten the burden of the adjustment for their partners thanks to higher inflation rates. Indeed, the current European difficulties do not seem to be solvable without a stronger fiscal integration, and without implication of the Northern countries. Many papers consider that putting the blame on the Southern countries and asking them for more austerity could only accentuate the crisis. The solution would lie in a real fiscal union and cooperation among the member countries of the monetary union. Holinski et al. [15] also mention that more budgetary coordination is necessary in Europe and that current account imbalances are a joint responsibility of Northern and Southern countries. Therefore, many papers seem to be in favor of a positive asymmetric demand shock (in particular, increasing wages in Germany) in order to reduce external imbalances in the EMU. In this context, what are the teachings of our model, regarding the possible benefits of specific demand shocks, in order to improve the global European economic framework?

Our model shows that in case of a positive symmetric demand shock, both monetary and budgetary policies are more recessionary in order to compensate for the consequences of the shock. Economic policies are then complementary, and the relative preferences of the authorities only contribute to determine their respective weights in the stabilization effort of these demand shocks. Whereas austerity measures have detrimental consequences, positive demand shocks would be beneficial to the reduction in budgetary deficits and indebtedness levels for the debtor Southern European countries. However, if the economic authorities are constrained in the use of their instruments, prices and economic activity levels then increase in parallel in all member countries of the monetary union. The consequences are therefore limited for the relative price competitiveness and the current accounts of the member countries of the monetary union. Indeed, positive demand shocks could contribute to reduce the differential in net foreign assets detained by the member countries of a monetary union, in particular if the stabilization effort mainly relies on the governments and not on the common central bank, but these variations would remain very limited. Moreover, external imbalances and indebtedness levels in a monetary union are more easily reduced by a positive symmetric demand shock if the debtor countries have a weaker price flexibility and imported inflation.

In case of an asymmetric demand shock, if the budgetary authorities are constrained in the use of their budgetary expenditure, the more restrictive budgetary policies cannot avoid the expansionary tensions in the countries positively affected whereas the more expansionary budgetary policies cannot avoid the recessionary tensions in the countries negatively affected by the shock. In these conditions, such a shock creates current account deficits in the countries affected by a positive demand shock and current account surpluses in the partner countries. So, according to our model, an asymmetric positive demand shock in the creditor Northern European countries (Germany or The Netherlands) would reduce the current account deficits and the external imbalances for the debtor Southern European countries. However, this would also increase the budgetary deficits and public debts and would create recessionary risks in these Southern European countries. Therefore, the main argument against an asymmetric (in comparison with a symmetric) demand shock in Europe is that it would increase the debt problems of the debtor Southern countries, instead of lightening their difficulties. Nevertheless, external imbalances would be reduced at a smaller cost for the indebtedness level if the countries negatively affected by the shock have the strongest monetary policy transmission parameters and the highest openness to trade. Therefore, a positive demand shock in Germany would be more beneficial in order to reduce the current account deficit of an open country like Ireland than for more closed countries like Spain or Greece. It would also be more beneficial if price flexibility was high in the EMU, whereas rigidities are still quite important in Europe today, in particular in labour markets.

\section{Appendices}

\section{A. Economic Activity and Inflation}

Solving (1) and (2) forwards and under the assumption that: $\lim _{T \rightarrow \infty} y_{i, t+T}=\lim _{T \rightarrow \infty} g_{i, t+T}=\lim _{T \rightarrow \infty} \pi_{i, t+T}=0$, we have

$$
\begin{aligned}
y_{i, t}^{d}= & -\sigma_{i} \sum_{T=0}^{\infty}\left\{E_{t}\left[i_{t+T}-\pi_{i, t+T+1}\right]-\bar{r}\right\} \\
& +\eta_{i} \sum_{T=0}^{\infty} E_{t}\left(\pi_{j, t+T}-\pi_{i, t+T}\right)+\left(1-\sigma_{i}\right) g_{i, t}+\varepsilon_{i, t}^{d}, \\
\pi_{i, t}= & k_{i} \sum_{T=0}^{\infty} E_{t}\left(b^{T} y_{i, t+T}\right)+v_{i} \sum_{T=0}^{\infty} E_{t}\left(b^{T} \pi_{j, t+T}\right)-\varepsilon_{i, t}^{s} .
\end{aligned}
$$

Then, by combining (A.1) and (A.2), we obtain

$$
\begin{aligned}
& {\left[1+\eta_{i} k_{i}\left(1-v_{j}\right)+\eta_{j} k_{j}\left(1-v_{i}\right)-v_{i} v_{j}\right] \pi_{i, t}} \\
& =\left(1+\eta_{j} k_{j}\right) k_{i} \sum_{T=0}^{\infty} b^{1+T} E_{t}\left(y_{i, t+T+1}\right) \\
& \quad+k_{j}\left(k_{i} \eta_{i}+v_{i}\right) \sum_{T=0}^{\infty} b^{1+T} E_{t}\left(y_{j, t+T+1}\right) \\
& \quad-\left[\left(1+\eta_{j} k_{j}\right) \sigma_{i} k_{i}+\sigma_{j} k_{j}\left(k_{i} \eta_{i}+v_{i}\right)\right]
\end{aligned}
$$




$$
\begin{aligned}
& \times \sum_{T=0}^{\infty}\left\{E_{t}\left[i_{t+T}\right]-\bar{r}\right\}+\left(1+\eta_{j} k_{j}\right) k_{i}\left[\left(1-\sigma_{i}\right) g_{i, t}+\varepsilon_{i, t}^{d}\right] \\
& +k_{j}\left(k_{i} \eta_{i}+v_{i}\right)\left[\left(1-\sigma_{j}\right) g_{j, t}+\varepsilon_{j, t}^{d}\right] \\
& -\left(1+\eta_{j} k_{j}\right) \varepsilon_{i, t}^{s}-\left(k_{i} \eta_{i}+v_{i}\right) \varepsilon_{j, t}^{s} \\
& +\left[\left(\sigma_{i}+\sigma_{i} \eta_{j} k_{j}-\eta_{i}\right) k_{i}+v_{i} k_{j} \eta_{j}\right] \sum_{T=0}^{\infty} E_{t}\left(\pi_{i, t+T+1}\right) \\
& +v_{j}\left(k_{i} \eta_{i}+v_{i}\right) \sum_{T=0}^{\infty} b^{1+T} E_{t}\left(\pi_{i, t+T+1}\right) \\
& +\left[k_{i} \eta_{i}+\left(\sigma_{j} k_{i} \eta_{i}+\sigma_{j} v_{i}-v_{i} \eta_{j}\right) k_{j}\right] \sum_{T=0}^{\infty} E_{t}\left(\pi_{j, t+T+1}\right) \\
& +v_{i}\left(1+\eta_{j} k_{j}\right) \sum_{T=0}^{\infty} b^{1+T} E_{t}\left(\pi_{j, t+T+1}\right) .
\end{aligned}
$$

\section{B. Definition of Optimal Economic Policies and Variables}

$(m)$ is the weight of the "Northern countries" in the monetary union.

The central bank minimizes its loss function. Therefore, with $\partial E_{t}\left(\pi_{t+T+1}\right) / \partial i_{t}=\partial E_{t}\left(y_{t+T+1}\right) / \partial i_{t}=\partial E_{t}\left(i_{t+T+1}\right) / \partial i_{t}=0$ for all $T \geq 0$ and using (3) and (4), $\partial L^{M} / \partial i_{t}=0$ implies

$$
\begin{aligned}
m_{1} i_{t}= & m_{2, n}\left[\left(1-\sigma_{n}\right) g_{n, t}+\varepsilon_{n, t}^{d}\right] \\
& +m_{2, s}\left[\left(1-\sigma_{s}\right) g_{s, t}+\varepsilon_{s, t}^{d}\right] \\
& +f\left[\varepsilon_{t}^{s}, \overline{\varepsilon_{t}^{s}}, \bar{r}, \sum_{T=0}^{\infty} E_{t}\left(y_{n, t+T+1}\right), \sum_{T=0}^{\infty} E_{t}\left(y_{s, t+T+1}\right),\right. \\
m_{1}= & (1+\delta) \alpha_{i}^{M} \\
& \quad\left[1+\eta_{T=0}^{\infty} E_{t}\left(\pi_{s, t+T+1}\right), \sum_{T=0}^{\infty} E_{t}\left(i_{t+T+1}\right), i_{t-1}\right] \\
& \left.+\alpha_{\pi}^{M}\left[\sigma_{n} k_{n}\left(m+v_{s}\right)+\eta_{s} k_{s}\left(1-v_{n}\right)-v_{n} v_{s}\right]_{s}^{2}+k_{s} \eta_{s}\right) \\
& \left.+\sigma_{s} k_{s}\left(1-m+m v_{n}+k_{n} \eta_{n}\right)\right]^{2} \\
& +\left(m k_{s}\left(1-v_{n}\right)\left(\sigma_{n} \eta_{s}+\sigma_{s} \eta_{n}\right)\right. \\
& +(1-m) k_{n}\left(1-v_{s}\right)\left(\sigma_{n} \eta_{s}+\sigma_{s} \eta_{n}\right) \\
& \left.\left.+\sigma_{s}-m \sigma_{s}\right)\left(1-v_{n} v_{s}\right)\right]^{2}>0
\end{aligned}
$$

$$
\begin{gathered}
m_{2, i}=\alpha_{\pi}^{M} k_{i}\left[\sigma_{i} k_{i}\left(m_{i}+v_{j}-m_{i} v_{j}+k_{j} \eta_{j}\right)\right. \\
\left.\quad+\sigma_{j} k_{j}\left(1-m_{i}+m_{i} v_{i}+k_{i} \eta_{i}\right)\right] \\
\times\left[m_{i}+k_{j} \eta_{j}+m_{j} v_{j}\right] \\
+\left[m_{i} k_{j}\left(1-v_{i}\right)\left(\sigma_{i} \eta_{j}+\sigma_{j} \eta_{i}\right)\right. \\
+\left(1-m_{i}\right) k_{i}\left(1-v_{j}\right)\left(\sigma_{i} \eta_{j}+\sigma_{j} \eta_{i}\right) \\
\left.+\left(m_{i} \sigma_{i}+\sigma_{j}-m_{i} \sigma_{j}\right)\left(1-v_{i} v_{j}\right)\right] \\
\times\left[m_{i}\left(1-v_{i} v_{j}\right)+m_{i} \eta_{j} k_{j}\left(1-v_{i}\right)\right. \\
\left.+m_{j} \eta_{j} k_{i}\left(1-v_{j}\right)\right]>0 .
\end{gathered}
$$

The government $(i)$ minimizes its loss function. Therefore, with $\partial E_{t}\left(\pi_{i, t+T+1}\right) / \partial g_{i, t}=\partial E_{t}\left(y_{i, t+T+1}\right) / \partial g_{i, t}=$ $\partial E_{t}\left(g_{i, t+T+1}\right) / \partial g_{i, t}=\partial E_{t}\left(\mathrm{ca}_{i, t+T+1}\right) / \partial g_{i, t}=0$ for all $T \geq 0$ and using (3), (4), and (7), $\partial L_{i}^{G} / \partial g_{i, t}=0$ implies

$$
\begin{aligned}
& m_{4, i} g_{i, t}=m_{5, i} i_{t}-m_{6, i} \varepsilon_{i, t}^{d}-k_{j} m_{9, i}\left[\left(1-\sigma_{j}\right) g_{j, t}+\varepsilon_{j, t}^{d}\right] \\
& +f\left[\varepsilon_{t}^{s}, \overline{\varepsilon_{t}^{s}}, \bar{r}, \sum_{T=0}^{\infty} E_{t}\left(y_{i, t+T+1}\right), \sum_{T=0}^{\infty} E_{t}\left(y_{j, t+T+1}\right)\right. \text {, } \\
& \left.\sum_{T=0}^{\infty} E_{t}\left(\pi_{j, t+T+1}\right), \sum_{T=0}^{\infty} E_{t}\left(i_{t+T+1}\right)\right], \\
& m_{4, i}=\alpha_{g}^{G}\left[1+\eta_{i} k_{i}\left(1-v_{j}\right)+\eta_{j} k_{j}\left(1-v_{i}\right)-v_{i} v_{j}\right]^{2} \\
& +\left(1-\sigma_{i}\right) m_{6, i}>0 \\
& m_{5, i}=\left(1-\sigma_{i}\right) \\
& \times\left\{\alpha_{\mathrm{ca}}^{G}\right. \\
& \times\left[\eta_{i} k_{i}\left(1-v_{j}\right)+\mathrm{nfa}_{i, t-1}\right. \\
& \left.\times\left(1-v_{i} v_{j}+k_{i}+k_{i} \eta_{j} k_{j}+\eta_{j} k_{j}-v_{i} \eta_{j} k_{j}\right)\right] \\
& \times\left[\eta_{i} \sigma_{i} k_{i}\left(1-v_{j}\right)-\eta_{i} \sigma_{j} k_{j}\left(1-v_{i}\right)+\mathrm{nfa}_{i, t-1} \sigma_{i}\right. \\
& \times\left(1+k_{i}+k_{i} \eta_{j} k_{j}-v_{i} v_{j}+k_{j} \eta_{j}-v_{i} k_{j} \eta_{j}\right) \\
& +\mathrm{nfa}_{i, t-1} \sigma_{j}\left(k_{j} k_{i} \eta_{i}+k_{j} v_{i}\right. \\
& \left.\left.+k_{j} \eta_{i}-k_{j} \eta_{i} v_{i}\right)\right]+\alpha_{\pi}^{G} \\
& \times\left(1+\eta_{j} k_{j}\right) k_{i}\left[\left(1+\eta_{j} k_{j}\right) \sigma_{i} k_{i}+\sigma_{j} k_{j}\left(k_{i} \eta_{i}+v_{i}\right)\right] \\
& +\left[1-v_{i} v_{j}+\eta_{j} k_{j}\left(1-v_{i}\right)\right] \\
& \left.\times\left[k_{j}\left(1-v_{i}\right)\left(\sigma_{j} \eta_{i}+\sigma_{i} \eta_{j}\right)+\sigma_{i}\left(1-v_{i} v_{j}\right)\right]\right\}>0 \text {, }
\end{aligned}
$$


ISRN Economics

13

$$
\begin{aligned}
m_{6, i}=\left(1-\sigma_{i}\right) & \\
\times & \left\{\alpha_{\mathrm{ca}}^{G}\right. \\
& \times\left[\eta_{i} k_{i}\left(1-v_{j}\right)+\mathrm{nfa}_{i, t-1}\right. \\
& \left.\times\left(1-v_{i} v_{j}+k_{i}+k_{i} \eta_{j} k_{j}+\eta_{j} k_{j}-v_{i} \eta_{j} k_{j}\right)\right]^{2} \\
& +\alpha_{\pi}^{G} k_{i}^{2}\left(1+\eta_{j} k_{j}\right)^{2} \\
& \left.+\left[1-v_{i} v_{j}+\eta_{j} k_{j}\left(1-v_{i}\right)\right]^{2}\right\} \\
m_{9, i}=(1- & \left.\sigma_{i}\right) \\
\times & \alpha_{\mathrm{ca}}^{G} \\
& \times\left[\eta_{i} k_{i}\left(1-v_{j}\right)+\mathrm{nfa}_{i, t-1}\right. \\
& \left.\times\left(1-v_{i} v_{j}+k_{i}+k_{i} \eta_{j} k_{j}+\eta_{j} k_{j}-v_{i} \eta_{j} k_{j}\right)\right] \\
& \times\left[\eta_{i}\left(1-v_{i}\right)-\mathrm{nfa}_{i, t-1}\left(k_{i} \eta_{i}+v_{i}+\eta_{i}-\eta_{i} v_{i}\right)\right] \\
& +\alpha_{\pi}^{G}\left(1+\eta_{j} k_{j}\right) k_{i}\left(k_{i} \eta_{i}+v_{i}\right) \\
& \left.\left(1-v_{i}\right) \eta_{i}\left[1-v_{i} v_{j}+\eta_{j} k_{j}\left(1-v_{i}\right)\right]\right\} .
\end{aligned}
$$

So, by combining (B.1) and (B.2), we have

$$
\begin{gathered}
{\left[1+\eta_{i} k_{i}\left(1-v_{j}\right)+\eta_{j} k_{j}\left(1-v_{i}\right)-v_{i} v_{j}\right]^{2} m_{10} i_{t}} \\
=\alpha_{g}^{G}\left[m_{2, i} m_{4, j}-m_{2, j}\left(1-\sigma_{j}\right) m_{7, j}\right. \\
\left.+m_{2, j} m_{4, i}-m_{2, i}\left(1-\sigma_{i}\right) m_{7, i}\right] \varepsilon_{t}^{d} \\
+\alpha_{g}^{G}\left[m_{2, i} m_{4, j}-m_{2, j}\left(1-\sigma_{j}\right) m_{7, j}\right. \\
\left.-m_{2, j} m_{4, i}+m_{2, i}\left(1-\sigma_{i}\right) m_{7, i}\right] \overline{\varepsilon_{t}^{d}} \\
+f\left[\varepsilon_{t}^{s}, \overline{\varepsilon_{t}^{s}}, \bar{r}_{T}, \sum_{T=0}^{\infty} E_{t}\left(y_{n, t+T+1}\right), \sum_{T=0}^{\infty} E_{t}\left(y_{s, t+T+1}\right)\right. \\
m_{10}=\left\{m_{1} m_{4, j} m_{4, i}-m_{2, i}\left(1-\sigma_{i}\right) m_{5, i} m_{4, j}\right. \\
\left.\quad m_{2, j}\left(1-\sigma_{j}\right) m_{5, j} m_{4, i}\left(\pi_{s, t+T+1}\right), \sum_{T=0}^{\infty} E_{t}\left(i_{t+T+1}\right)\right] \\
+\left(m_{2, j} m_{5, i} m_{7, j}+m_{2, i} m_{5, j} m_{7, i}-m_{1} m_{7, j} m_{7, i}\right) \\
\left.\times\left(1-\sigma_{j}\right)\left(1-\sigma_{i}\right)\right\} \\
\left.\times\left(1+\eta_{i} k_{i}\left(1-v_{j}\right)+\eta_{j} k_{j}\left(1-v_{i}\right)-v_{i} v_{j}\right]^{4}\right)^{-1}>0
\end{gathered}
$$

$$
\begin{aligned}
& {\left[1+\eta_{i} k_{i}\left(1-v_{j}\right)+\eta_{j} k_{j}\left(1-v_{i}\right)-v_{i} v_{j}\right]^{4} m_{10} g_{i, t}} \\
& =-\left\{\left[m_{1} m_{4, j}-m_{2, j}\left(1-\sigma_{j}\right) m_{5, j}\right] m_{6, i}\right. \\
& +\left(1-\sigma_{j}\right) m_{7, i}\left(m_{2, i} m_{5, j}-m_{1} m_{7, j}\right) \\
& \left.+\left[\left(1-\sigma_{j}\right) m_{2, j} m_{7, j}-m_{2, i} m_{4, j}\right] m_{5, i}\right\} \varepsilon_{i, t}^{d} \\
& +\alpha_{g}^{G}\left[1+\eta_{i} k_{i}\left(1-v_{j}\right)+\eta_{j} k_{j}\left(1-v_{i}\right)-v_{i} v_{j}\right]^{2} \\
& \times\left(m_{2, j} m_{5, i}-m_{7, i} m_{1}\right) \varepsilon_{j, t}^{d} \\
& +f\left[\varepsilon_{t}^{s}, \overline{\varepsilon_{t}^{s}}, \bar{r}, \sum_{T=0}^{\infty} E_{t}\left(y_{i, t+T+1}\right), \sum_{T=0}^{\infty} E_{t}\left(y_{j, t+T+1}\right),\right. \\
& \left.\sum_{T=0}^{\infty} E_{t}\left(\pi_{j, t+T+1}\right), \sum_{T=0}^{\infty} E_{t}\left(i_{t+T+1}\right)\right] .
\end{aligned}
$$

Then, by combining the economic policies (B.3) and (B.4) with the economic variables in (3), (4), and (7), we have

$$
\begin{aligned}
& m_{10} \pi_{i, t}=\alpha_{g}^{G} m_{19, i} \varepsilon_{t}^{d}+\alpha_{g}^{G} m_{20, i} \overline{\varepsilon_{t}^{d}} \\
& +f\left[\varepsilon_{t}^{s}, \overline{\varepsilon_{t}^{s}}, \bar{r}, \sum_{T=0}^{\infty} E_{t}\left(y_{i, t+T+1}\right), \sum_{T=0}^{\infty} E_{t}\left(y_{j, t+T+1}\right),\right. \\
& \left.\sum_{T=0}^{\infty} E_{t}\left(\pi_{j, t+T+1}\right), \sum_{T=0}^{\infty} E_{t}\left(i_{t+T+1}\right)\right] \text {, } \\
& m_{19, i}=(1+\delta) \alpha_{i}^{M} \alpha_{g}^{G} \\
& \times\left[1+\eta_{i} k_{i}\left(1-v_{j}\right)+\eta_{j} k_{j}\left(1-v_{i}\right)-v_{i} v_{j}\right] \\
& \times\left[\left(1+\eta_{j} k_{j}\right) k_{i}+k_{j}\left(k_{i} \eta_{i}+v_{i}\right)\right] \\
& +(1+\delta) \alpha_{i}^{M} \alpha_{\pi}^{G} k_{i}\left(1+\eta_{i} k_{i}\right) k_{j}^{2}\left(1-\sigma_{j}\right)^{2} \\
& +(1+\delta) \alpha_{i}^{M} \alpha_{c a}^{G} \\
& \times\left\{\left[\eta_{j} k_{j}+\mathrm{nfa}_{j, t-1}\left(1+k_{j}\right)\right]\left(1-\sigma_{j}\right)^{2} k_{i}\right. \\
& \times\left[\eta_{j} k_{j}\left(1-v_{i}\right)+\mathrm{nfa}_{j, t-1}\right. \\
& \left.\times\left(1-v_{i} v_{j}+k_{j}+k_{i} \eta_{i} k_{j}+\eta_{i} k_{i}-v_{j} \eta_{i} k_{i}\right)\right] \\
& +\left(1-\sigma_{i}\right)^{2} k_{j}\left[\eta_{i} k_{i}+\mathrm{nfa}_{i, t-1} v_{i}\right] \\
& \times\left[\eta_{i} k_{i}\left(1-v_{j}\right)+\mathrm{nfa}_{i, t-1}\right. \\
& \left.\left.\times\left(1-v_{i} v_{j}+k_{i}+k_{i} \eta_{j} k_{j}+\eta_{j} k_{j}-v_{i} \eta_{j} k_{j}\right)\right]\right\} \\
& +(1+\delta) \alpha_{i}^{M}
\end{aligned}
$$




$$
\begin{aligned}
& \times\left\{\left(1-\sigma_{j}\right)^{2} k_{i}\left[1-v_{i} v_{j}+\eta_{i} k_{i}\left(1-v_{j}\right)\right]\right. \\
& \left.+\left(m_{i} \sigma_{i}+\sigma_{j}-m_{i} \sigma_{j}\right)\left(1-v_{i} v_{j}\right)\right] \\
& \left.+\left(1-\sigma_{i}\right)^{2}\left[1-v_{i} v_{j}+\eta_{j} k_{j}\left(1-v_{i}\right)\right] k_{j} v_{i}\right\} \\
& \times\left(\sigma_{i}+\sigma_{j}\right)\left[\left(1-m_{i}\right) k_{i}-m_{i} k_{j} v_{i}\right], \\
& +\alpha_{\pi}^{M} \alpha_{g}^{G}\left[\sigma_{i} k_{i}\left(m_{i}+v_{j}-m_{i} v_{j}+k_{j} \eta_{j}\right)\right. \\
& \left.+\sigma_{j} k_{j}\left(1-m_{i}+m_{i} v_{i}+k_{i} \eta_{i}\right)\right] \\
& \times\left(\sigma_{j}-\sigma_{i}\right) k_{j} k_{i}\left(1-m_{i}\right) \\
& +\alpha_{g}^{G}\left[m_{i} k_{j}\left(1-v_{i}\right)\left(\sigma_{j} \eta_{i}+\eta_{j} \sigma_{i}\right)\right. \\
& +\left(1-m_{i}\right) k_{i}\left(1-v_{j}\right)\left(\sigma_{j} \eta_{i}+\eta_{j} \sigma_{i}\right) \\
& \left.+\left(m_{i} \sigma_{i}+\sigma_{j}-m_{i} \sigma_{j}\right)\left(1-v_{i} v_{j}\right)\right] \\
& \times\left(\sigma_{j}-\sigma_{i}\right)\left[\left(1-m_{i}\right) k_{i}-m_{i} k_{j} v_{i}\right], \\
& m_{20, i}=(1+\delta) \alpha_{i}^{M} \alpha_{g}^{G} \\
& \times\left[1+\eta_{i} k_{i}\left(1-v_{j}\right)+\eta_{j} k_{j}\left(1-v_{i}\right)-v_{i} v_{j}\right] \\
& \times\left[\left(1+\eta_{j} k_{j}\right) k_{i}-k_{j}\left(k_{i} \eta_{i}+v_{i}\right)\right] \\
& +(1+\delta) \alpha_{i}^{M} \alpha_{\pi}^{G} k_{i}\left(1+\eta_{i} k_{i}\right) k_{j}^{2}\left(1-\sigma_{j}\right)^{2} \\
& +(1+\delta) \alpha_{i}^{M} \alpha_{\mathrm{ca}}^{G} \\
& \times\left\{\left[\eta_{j} k_{j}+\mathrm{nfa}_{j, t-1}\left(1+k_{j}\right)\right]\left(1-\sigma_{j}\right)^{2} k_{i}\right. \\
& \times\left[\eta_{j} k_{j}\left(1-v_{i}\right)+\mathrm{nfa}_{j, t-1}\right. \\
& \left.\times\left(1-v_{i} v_{j}+k_{j}+k_{i} \eta_{i} k_{j}+\eta_{i} k_{i}-v_{j} \eta_{i} k_{i}\right)\right] \\
& -\left(1-\sigma_{i}\right)^{2} k_{j}\left[\eta_{i} k_{i}+\mathrm{nfa}_{i, t-1} v_{i}\right] \\
& \times\left[\eta_{i} k_{i}\left(1-v_{j}\right)+\mathrm{nfa}_{i, t-1}\right. \\
& \left.\left.\times\left(1-v_{i} v_{j}+k_{i}+k_{i} \eta_{j} k_{j}+\eta_{j} k_{j}-v_{i} \eta_{j} k_{j}\right)\right]\right\} \\
& +(1+\delta) \alpha_{i}^{M} \\
& \times\left\{\left(1-\sigma_{j}\right)^{2} k_{i}\left[1-v_{i} v_{j}+\eta_{i} k_{i}\left(1-v_{j}\right)\right]\right. \\
& \left.-\left(1-\sigma_{i}\right)^{2}\left[1-v_{i} v_{j}+\eta_{j} k_{j}\left(1-v_{i}\right)\right] k_{j} v_{i}\right\} \\
& +\alpha_{\pi}^{M} \alpha_{g}^{G}\left[\sigma_{i} k_{i}\left(m_{i}+v_{j}-m_{i} v_{j}+k_{j} \eta_{j}\right)\right. \\
& \left.+\sigma_{j} k_{j}\left(1-m_{i}+m_{i} v_{i}+k_{i} \eta_{i}\right)\right] \\
& \times\left(\sigma_{i}+\sigma_{j}\right) k_{i} k_{j}\left(1-m_{i}\right) \\
& +\alpha_{g}^{G}\left[m_{i} k_{j}\left(1-v_{i}\right)\left(\sigma_{j} \eta_{i}+\eta_{j} \sigma_{i}\right)\right. \\
& +\left(1-m_{i}\right) k_{i}\left(1-v_{j}\right)\left(\sigma_{j} \eta_{i}+\eta_{j} \sigma_{i}\right) \\
& m_{10} y_{i, t}=\alpha_{g}^{G} m_{21, i} \varepsilon_{t}^{d}+\alpha_{g}^{G} m_{22, i} \overline{\varepsilon_{t}^{d}} \\
& +f\left[\varepsilon_{t}^{s}, \overline{\varepsilon_{t}^{s}}, \bar{r}, \sum_{T=0}^{\infty} E_{t}\left(y_{i, t+T+1}\right), \sum_{T=0}^{\infty} E_{t}\left(y_{j, t+T+1}\right),\right. \\
& \left.\sum_{T=0}^{\infty} E_{t}\left(\pi_{j, t+T+1}\right), \sum_{T=0}^{\infty} E_{t}\left(i_{t+T+1}\right)\right], \\
& m_{21, i}=(1+\delta) \alpha_{i}^{M} \alpha_{g}^{G} \\
& \times\left[1+\eta_{i} k_{i}\left(1-v_{j}\right)+\eta_{j} k_{j}\left(1-v_{i}\right)-v_{i} v_{j}\right] \\
& \times\left[1-v_{i} v_{j}+\left(\eta_{i}+\eta_{j}\right) k_{j}\left(1-v_{i}\right)\right] \\
& +(1+\delta) \alpha_{i}^{M} \alpha_{\mathrm{ca}}^{G} \\
& \times\left\{\left(1-\sigma_{j}\right)^{2}\right. \\
& \times\left[\eta_{j} k_{j}\left(1-v_{i}\right)+\mathrm{nfa}_{j, t-1}\right. \\
& \left.\times\left(1-v_{i} v_{j}+k_{j}+k_{i} \eta_{i} k_{j}+\eta_{i} k_{i}-v_{j} \eta_{i} k_{i}\right)\right] \\
& \times\left[\eta_{j} k_{j}\left(1-v_{i}\right)+\mathrm{nfa}_{j, t-1}\left(1-v_{i} v_{j}+k_{j}\right)\right] \\
& +\left(1-\sigma_{i}\right)^{2} k_{j}\left[\eta_{i}\left(1-v_{i}\right)-\mathrm{nfa}_{i, t-1} v_{i}\right] \\
& \times\left[\eta_{i} k_{i}\left(1-v_{j}\right)+\mathrm{nfa}_{i, t-1}\right. \\
& \left.\left.\times\left(1-v_{i} v_{j}+k_{i}+k_{i} \eta_{j} k_{j}+\eta_{j} k_{j}-v_{i} \eta_{j} k_{j}\right)\right]\right\} \\
& +(1+\delta) \alpha_{i}^{M} \alpha_{\pi}^{G} k_{j}\left[k_{j}\left(1-\sigma_{j}\right)^{2}\left(1+\eta_{i} k_{i}\right)\right. \\
& \left.-k_{i}\left(1-\sigma_{i}\right)^{2} v_{i}\left(1+\eta_{j} k_{j}\right)\right] \\
& +(1+\delta) \alpha_{i}^{M}\left(1-\sigma_{j}\right)^{2} \\
& \times\left[1-v_{i} v_{j}+\eta_{i} k_{i}\left(1-v_{j}\right)\right]\left(1-v_{i} v_{j}\right) \\
& +\alpha_{\pi}^{M} \alpha_{g}^{G}\left[\sigma_{i} k_{i}\left(m_{i}+v_{j}-m_{i} v_{j}+k_{j} \eta_{j}\right)\right. \\
& \left.+\sigma_{j} k_{j}\left(1-m_{i}+m_{i} v_{i}+k_{i} \eta_{i}\right)\right] \\
& \times\left(\sigma_{j}-\sigma_{i}\right) k_{j}\left(1-m_{i}+m_{i} v_{i}\right) \\
& +\alpha_{g}^{G}\left[m_{i} k_{j}\left(1-v_{i}\right)\left(\sigma_{j} \eta_{i}+\eta_{j} \sigma_{i}\right)\right. \\
& +\left(1-m_{i}\right) k_{i}\left(1-v_{j}\right)\left(\sigma_{j} \eta_{i}+\eta_{j} \sigma_{i}\right) \\
& \left.+\left(m_{i} \sigma_{i}+\sigma_{j}-m_{i} \sigma_{j}\right)\left(1-v_{i} v_{j}\right)\right] \\
& \times\left(\sigma_{j}-\sigma_{i}\right)\left(1-m_{i}\right)\left(1-v_{i} v_{j}\right),
\end{aligned}
$$


ISRN Economics

15

$$
\begin{aligned}
& m_{22, i}=(1+\delta) \alpha_{i}^{M} \alpha_{g}^{G} \\
& m_{23, i}=-(1+\delta) \alpha_{i}^{M} \alpha_{g}^{G} \\
& \times\left[1+\eta_{i} k_{i}\left(1-v_{j}\right)+\eta_{j} k_{j}\left(1-v_{i}\right)-v_{i} v_{j}\right] \\
& \times\left[1+\eta_{i} k_{i}\left(1-v_{j}\right)+\eta_{j} k_{j}\left(1-v_{i}\right)-v_{i} v_{j}\right] \\
& \times\left[1-v_{i} v_{j}+\left(\eta_{j}-\eta_{i}\right) k_{j}\left(1-v_{i}\right)\right] \\
& \times\left[\eta_{i}\left(1-v_{j}\right) k_{i}-\eta_{i} k_{j}\left(1-v_{i}\right)\right. \\
& +(1+\delta) \alpha_{i}^{M} \alpha_{\pi}^{G} k_{j} \\
& +\operatorname{nfa}_{i, t-1}\left(1-v_{i} v_{j}+v_{i} k_{j}\right) \\
& \times\left[k_{j}\left(1-\sigma_{j}\right)^{2}\left(1+\eta_{i} k_{i}\right)+k_{i}\left(1-\sigma_{i}\right)^{2} v_{i}\left(1+\eta_{j} k_{j}\right)\right] \\
& +\operatorname{nfa}_{i, t-1}\left(\eta_{i}+\eta_{j}\right) k_{j}\left(1-v_{i}\right) \\
& +(1+\delta) \alpha_{i}^{M} \alpha_{c a}^{G} \\
& \left.+\operatorname{nfa}_{i, t-1}\left(1+\eta_{j} k_{j}+\eta_{i} k_{j}\right) k_{i}\right] \\
& \times\left\{\left(1-\sigma_{j}\right)^{2}\right. \\
& +(1+\delta) \alpha_{i}^{M} \alpha_{\pi}^{G} k_{j} \\
& \times\left[\eta_{j} k_{j}\left(1-v_{i}\right)+\mathrm{nfa}_{j, t-1}\right. \\
& \times\left\{k_{i}\left(1-\sigma_{i}\right)^{2}\left(1+\eta_{j} k_{j}\right)\left[\eta_{i} k_{i}+v_{i} \mathrm{nfa}_{i, t-1}\right]\right. \\
& \left.\times\left(1-v_{i} v_{j}+k_{j}+k_{i} \eta_{i} k_{j}+\eta_{i} k_{i}-v_{j} \eta_{i} k_{i}\right)\right] \\
& \left.-k_{j}\left(1-\sigma_{j}\right)^{2}\left(1+\eta_{i} k_{i}\right)\left[\mathrm{nfa}_{i, t-1}\left(1+k_{i}\right)+\eta_{i} k_{i}\right]\right\} \\
& \times\left[\eta_{j} k_{j}\left(1-v_{i}\right)+\mathrm{nfa}_{j, t-1}\left(1-v_{i} v_{j}+k_{j}\right)\right] \\
& -\left(1-\sigma_{i}\right)^{2} k_{j}\left[\eta_{i}\left(1-v_{i}\right)-\mathrm{nfa}_{i, t-1} v_{i}\right] \\
& \times\left[\eta_{i} k_{i}\left(1-v_{j}\right)+\mathrm{nfa}_{i, t-1}\right. \\
& \left.\left.\times\left(1-v_{i} v_{j}+k_{i}+k_{i} \eta_{j} k_{j}+\eta_{j} k_{j}-v_{i} \eta_{j} k_{j}\right)\right]\right\} \\
& +(1+\delta) \alpha_{i}^{M}\left(1-\sigma_{j}\right)^{2}\left[1-v_{i} v_{j}+\eta_{i} k_{i}\left(1-v_{j}\right)\right] \\
& \times\left(1-v_{i} v_{j}\right) \\
& +\alpha_{\pi}^{M} \alpha_{g}^{G} \\
& \times\left[\sigma_{i} k_{i}\left(m_{i}+v_{j}-m_{i} v_{j}+k_{j} \eta_{j}\right)\right. \\
& \left.+\sigma_{j} k_{j}\left(1-m_{i}+m_{i} v_{i}+k_{i} \eta_{i}\right)\right] \\
& \times\left(\sigma_{i}+\sigma_{j}\right) k_{j}\left(1-m_{i}+m_{i} v_{i}\right) \\
& +\alpha_{g}^{G}\left[m_{i} k_{j}\left(1-v_{i}\right)\left(\sigma_{j} \eta_{i}+\eta_{j} \sigma_{i}\right)\right. \\
& +\left(1-m_{i}\right) k_{i}\left(1-v_{j}\right)\left(\sigma_{j} \eta_{i}+\eta_{j} \sigma_{i}\right) \\
& \left.+\left(m_{i} \sigma_{i}+\sigma_{j}-m_{i} \sigma_{j}\right)\left(1-v_{i} v_{j}\right)\right]\left(\sigma_{i}+\sigma_{j}\right) \\
& \times\left(1-m_{i}\right)\left(1-v_{i} v_{j}\right), \\
& -(1+\delta) \alpha_{i}^{M} \alpha_{\mathrm{ca}}^{G}\left(1-\sigma_{j}\right)^{2} \\
& \times\left[\eta_{j} k_{j}\left(1-v_{i}\right)+\mathrm{nfa}_{j, t-1}\right. \\
& \left.\times\left(1-v_{i} v_{j}+k_{j}+k_{i} \eta_{i} k_{j}+\eta_{i} k_{i}-v_{j} \eta_{i} k_{i}\right)\right] \\
& \times\left[\mathrm{nfa}_{i, t-1} \eta_{j} k_{j}\left(1-v_{i}+k_{i}\right)\right. \\
& +\operatorname{nfa}_{j, t-1} \eta_{i}\left(1-v_{j}+k_{j}\right) k_{i} \\
& \left.+\operatorname{nfa}_{i, t-1} \mathrm{nfa}_{j, t-1}\left(1-v_{i} v_{j}+k_{j}+k_{i}+k_{j} k_{i}\right)\right] \\
& +(1+\delta) \alpha_{i}^{M} \\
& \times\left\{\left(1-\sigma_{i}\right)^{2}\right. \\
& \times\left[1-v_{i} v_{j}+\eta_{j} k_{j}\left(1-v_{i}\right)\right] k_{j} \\
& \times\left[\eta_{i}\left(1-v_{i}\right)-v_{i} \mathrm{nfa}_{i, t-1}\right] \\
& -\left(1-\sigma_{j}\right)^{2}\left[1-v_{i} v_{j}+\eta_{i} k_{i}\left(1-v_{j}\right)\right] \\
& \left.\times\left[\eta_{i} k_{i}\left(1-v_{j}\right)+\operatorname{nfa}_{i, t-1}\left(1-v_{i} v_{j}+k_{i}\right)\right]\right\} \\
& +\alpha_{\pi}^{M} \alpha_{g}^{G}\left[\sigma_{i} k_{i}\left(m_{i}+v_{j}-m_{i} v_{j}+k_{j} \eta_{j}\right)\right. \\
& \left.+\sigma_{j} k_{j}\left(1-m_{i}+m_{i} v_{i}+k_{i} \eta_{i}\right)\right] \\
& \times\left(\sigma_{i}-\sigma_{j}\right) k_{j} \\
& \times\left[k_{i} \eta_{i}+\mathrm{nfa}_{i, t-1}\left(1-m_{i}+m_{i} v_{i}+k_{i}-m_{i} k_{i}\right)\right] \\
& +\alpha_{g}^{G}\left[m_{i} k_{j}\left(1-v_{i}\right)\left(\sigma_{i} \eta_{j}+\sigma_{j} \eta_{i}\right)\right. \\
& +\left(1-m_{i}\right) k_{i}\left(1-v_{j}\right)\left(\sigma_{i} \eta_{j}+\sigma_{j} \eta_{i}\right) \\
& \left.+\left(m_{i} \sigma_{i}+\sigma_{j}-m_{i} \sigma_{j}\right)\left(1-v_{i} v_{j}\right)\right]\left(\sigma_{i}-\sigma_{j}\right) \\
& \times\left\{\left[\left(1-m_{i}\right) k_{i}\left(1-v_{j}\right)+m_{i} k_{j}\left(1-v_{i}\right)\right] \eta_{i}\right. \\
& \left.+\mathrm{nfa}_{i, t-1}\left[\left(1-m_{i}\right)\left(1-v_{i} v_{j}+k_{i}\right)-m_{i} k_{j} v_{i}\right]\right\}, \\
& m_{10} \mathrm{ca}_{i, t}=\alpha_{g}^{G} m_{23, i} \varepsilon_{t}^{d}+\alpha_{g}^{G} m_{24, i} \overline{\varepsilon_{t}^{d}} \\
& +f\left[\varepsilon_{t}^{s}, \overline{\varepsilon_{t}^{s}}, \bar{r}, \sum_{T=0}^{\infty} E_{t}\left(y_{i, t+T+1}\right), \sum_{T=0}^{\infty} E_{t}\left(y_{j, t+T+1}\right),\right. \\
& \left.\sum_{T=0}^{\infty} E_{t}\left(\pi_{j, t+T+1}\right), \sum_{T=0}^{\infty} E_{t}\left(i_{t+T+1}\right)\right],
\end{aligned}
$$




$$
\begin{aligned}
& m_{24, i}=-(1+\delta) \alpha_{i}^{M} \alpha_{g}^{G} \\
& \times\left[1+\eta_{i} k_{i}\left(1-v_{j}\right)+\eta_{j} k_{j}\left(1-v_{i}\right)-v_{i} v_{j}\right] \\
& \times\left[\left(1-k_{i} \eta_{i} k_{j}+k_{i} \eta_{j} k_{j}-v_{i} k_{j}-\eta_{i} k_{j}\right.\right. \\
& \left.+\eta_{j} k_{j}+v_{i} \eta_{i} k_{j}-\eta_{j} k_{j} v_{i}+k_{i}-v_{i} v_{j}\right) \mathrm{nfa}_{i, t-1} \\
& \left.+\eta_{i} k_{j}\left(1-v_{i}\right)+\eta_{i}\left(1-v_{j}\right) k_{i}\right] \\
& -(1+\delta) \alpha_{i}^{M} \alpha_{\pi}^{G} k_{j} \\
& \times\left\{k_{j}\left(1-\sigma_{j}\right)^{2}\left(1+\eta_{i} k_{i}\right)\left[\mathrm{nfa}_{i, t-1}\left(1+k_{i}\right)+\eta_{i} k_{i}\right]\right. \\
& \left.+k_{i}\left(1-\sigma_{i}\right)^{2}\left(1+\eta_{j} k_{j}\right)\left[\eta_{i} k_{i}+v_{i} \mathrm{nfa}_{i, t-1}\right]\right\} \\
& -(1+\delta) \alpha_{i}^{M} \alpha_{c a}^{G}\left(1-\sigma_{j}\right)^{2} \\
& \times\left[\eta_{j} k_{j}\left(1-v_{i}\right)+\mathrm{nfa}_{j, t-1}\right. \\
& \left.\times\left(1-v_{i} v_{j}+k_{j}+k_{i} \eta_{i} k_{j}+\eta_{i} k_{i}-v_{j} \eta_{i} k_{i}\right)\right] \\
& \times\left[\mathrm{nfa}_{i, t-1} \eta_{j} k_{j}\left(1-v_{i}+k_{i}\right)\right. \\
& +\operatorname{nfa}_{j, t-1} \eta_{i}\left(1-v_{j}+k_{j}\right) k_{i} \\
& \left.+\mathrm{nfa}_{i, t-1} \mathrm{nfa}_{j, t-1}\left(1-v_{i} v_{j}+k_{j}+k_{i}+k_{j} k_{i}\right)\right] \\
& -(1+\delta) \alpha_{i}^{M} \\
& \times\left\{\left(1-\sigma_{j}\right)^{2}\left[1-v_{i} v_{j}+\eta_{i} k_{i}\left(1-v_{j}\right)\right]\right. \\
& \times\left[\eta_{i} k_{i}\left(1-v_{j}\right)+\mathrm{nfa}_{i, t-1}\left(1-v_{i} v_{j}+k_{i}\right)\right] \\
& +\left(1-\sigma_{i}\right)^{2}\left[1-v_{i} v_{j}+\eta_{j} k_{j}\left(1-v_{i}\right)\right] k_{j} \\
& \left.\times\left[\eta_{i}\left(1-v_{i}\right)-v_{i} \mathrm{nfa}_{i, t-1}\right]\right\} \\
& -\alpha_{\pi}^{M} \alpha_{g}^{G}\left[\sigma_{i} k_{i}\left(m_{i}+v_{j}-m_{i} v_{j}+k_{j} \eta_{j}\right)+\sigma_{j} k_{j}\right. \\
& \left.\times\left(1-m_{i}+m_{i} v_{i}+k_{i} \eta_{i}\right)\right]\left(\sigma_{i}+\sigma_{j}\right) k_{j} \\
& \times\left[k_{i} \eta_{i}+\mathrm{nfa}_{i, t-1}\left(1-m_{i}+m_{i} v_{i}+k_{i}-m_{i} k_{i}\right)\right] \\
& -\alpha_{g}^{G}\left[m_{i} k_{j}\left(1-v_{i}\right)\left(\sigma_{i} \eta_{j}+\sigma_{j} \eta_{i}\right)\right. \\
& +\left(1-m_{i}\right) k_{i}\left(1-v_{j}\right)\left(\sigma_{i} \eta_{j}+\sigma_{j} \eta_{i}\right) \\
& \left.+\left(m_{i} \sigma_{i}+\sigma_{j}-m_{i} \sigma_{j}\right)\left(1-v_{i} v_{j}\right)\right]\left(\sigma_{i}+\sigma_{j}\right) \\
& \times\left\{\eta_{i}\left[\left(1-m_{i}\right)\left(1-v_{j}\right) k_{i}+k_{j}\left(1-v_{i}\right) m_{i}\right]\right. \\
& \left.+\mathrm{nfa}_{i, t-1}\left[\left(1-m_{i}\right)\left(1-v_{i} v_{j}+k_{i}\right)-m_{i} k_{j} v_{i}\right]\right\} \text {. }
\end{aligned}
$$

\section{Conflict of Interests}

There is no conflict of interests regarding the publication of this paper.

\section{References}

[1] F. Jaumotte and P. Sodsriwiboon, "Current account imbalances in the southern Euro area," IMF Working Paper WP/10/139, 2010.

[2] G. Schnabl and T. Wollmershäuser, "Fiscal divergence and current account imbalances in Europe," CESifo Working Paper 4108, 2013.

[3] E. Stockhammer, Peripheral Europe's Debt and German Wages. the Role of Wage Policy in the Euro Area, Research on Money and Finance Discussion Paper, no. 29, School of Oriental and African Studies, Department of Economics, 2011.

[4] J. Uxo, J. Paul, and E. Febrero, "Current account imbalances in the monetary union and the great recession: causes and policies," Panoeconomics, vol. 5, pp. 571-592, 2011.

[5] M. Higgins and T. Klitgaard, "Savings imbalances and the Euro area sovereign debt crisis," Current Issues in Economics and Finance, vol. 17, no. 5, 2011.

[6] D. Gros, "Adjustment difficulties in the GIPSY Club," CEPS Working Document 326, Centre for European Policy Studies, 2010.

[7] S. Cesaratto, "Controversial and novel features of the Eurozone crisis as a balance of payments crisis," Tech. Rep. 640, Quaderni del Dipartimento di Economia e Statistica; Università di Siena, 2012.

[8] S. Tilford and P. Whyte, Why Stricter Rules Threaten the Eurozone, Centre for European Reform; Essay, 2011.

[9] M. G. Arghyrou and G. Chortareas, "Current account imbalances and real exchange rates in the Euro area," Review of International Economics, vol. 16, no. 4, pp. 747-764, 2008.

[10] F. Giavazzi and L. Spaventa, "Way the current account may matter in a monetary union-lessons from the financial crisis in the Euro area," CEPR Discussion Paper 8008, 2010.

[11] R. R. Canale and U. Marani, "Current account and fiscal imbalances in the Euro-area: siamese twins in an asymmetrical currency union," Working Paper 659, Università degli Studi di Siena, 2012.

[12] D. Gros, "Macroeconomic imbalances in the Euro area: symptom or cause of the crisis?" CEPS Policy Brief 266, 2012.

[13] P. De Grauwe and J. Yuemei, "Self-fulfilling crises in the Eurozone: an empirical test," CeSifo Working Paper 3821, 2012.

[14] P. Alessandrini, M. Fratianni, A. Hughes Hallett, and A. F. Presbitero, "External imbalances and financial fragility in the Euro area," MoFIR Working Paper 66, 2012.

[15] N. Holinski, C. Kool, and J. Muysken, "Persistent macroeconomic imbalances in the euro area: causes and consequences," Federal Reserve Bank of St. Louis Review, vol. 94, no. 1, pp. 1-20, 2012.

[16] S. Merler and J. Pisani-Ferry, "The simple macroeconomics of north and south in EMU," Bruegel Working Paper 2012/12, 2012.

[17] P. De Grauwe, "In search of symmetry in the Eurozone," CEPS Policy Brief 268, 2012.

[18] G. Horn, J. Heike, and R. Zwiener, Global Imbalances: Cause of the Crisis and Solution Strategies for Germany, Policy Brief; Macroeconomic Policy Institute, 2009. 
[19] L. Lieb, "Taking real wage rigidities seriously: implications for optimal policy design in a currency union," International Economic Journal, vol. 26, no. 1, pp. 37-68, 2012.

[20] J. Galí and T. Monacelli, "Optimal monetary and fiscal policy in a currency union," Journal of International Economics, vol. 76, no. 1, pp. 116-132, 2008.

[21] L. Vogel, W. Roeger, and B. Herz, "Optimal simple rules for fiscal policy in a monetary union," BGPE Discussion Paper 21, Bayreuth University, 2006. 


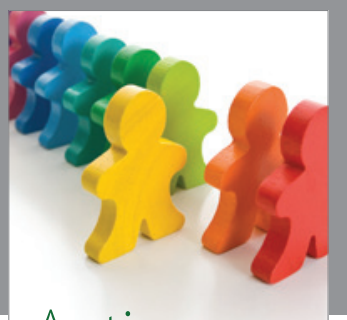

Autism

Research and Treatment
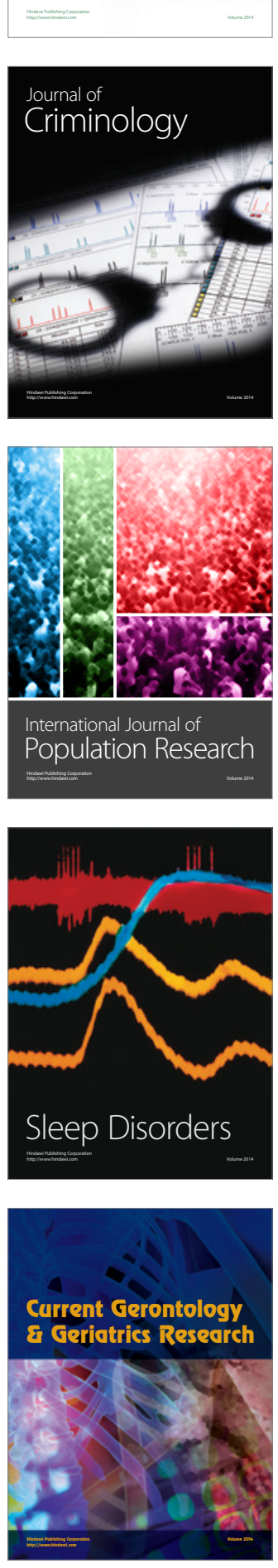
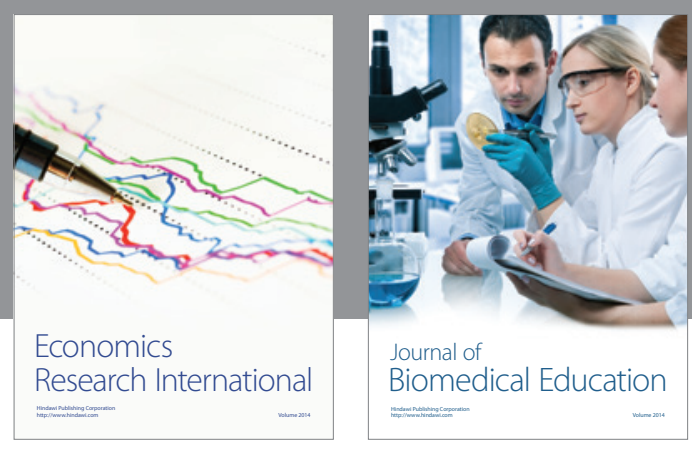

Journal of

Biomedical Education

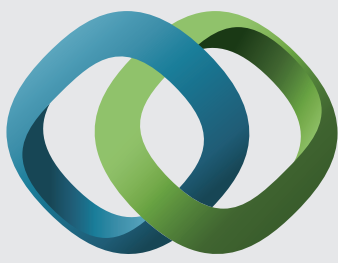

\section{Hindawi}

Submit your manuscripts at

http://www.hindawi.com
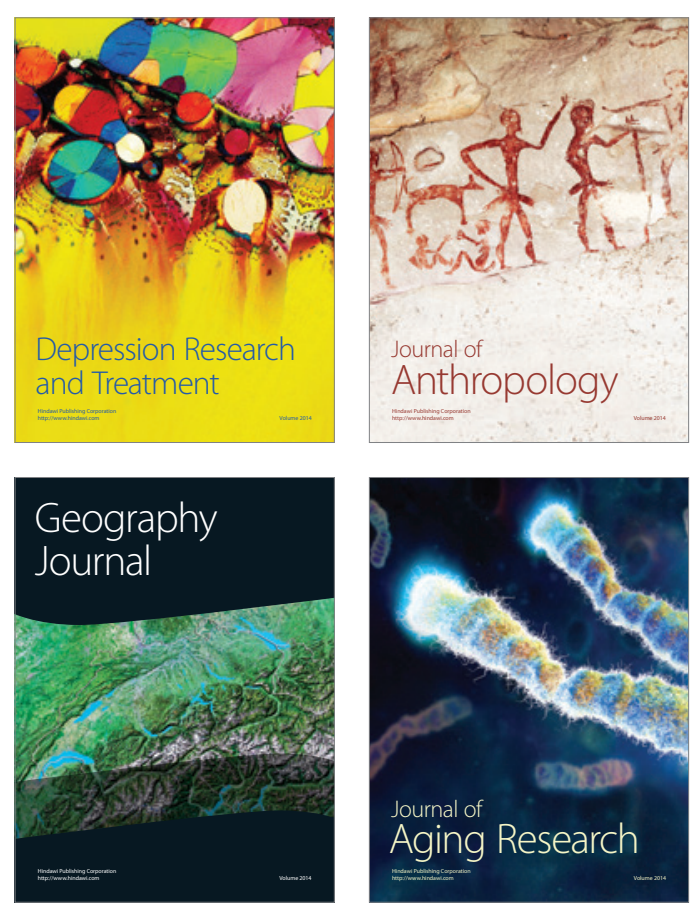

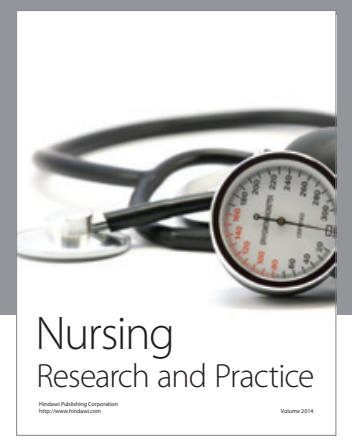

Nursing

Research and Practice

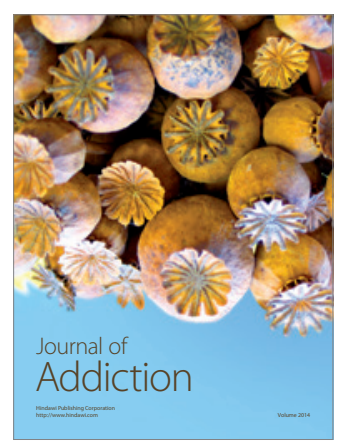

Child Development

Research

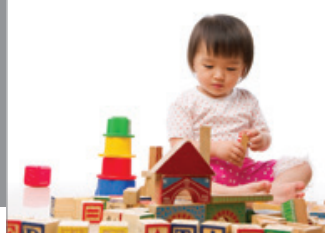

迥
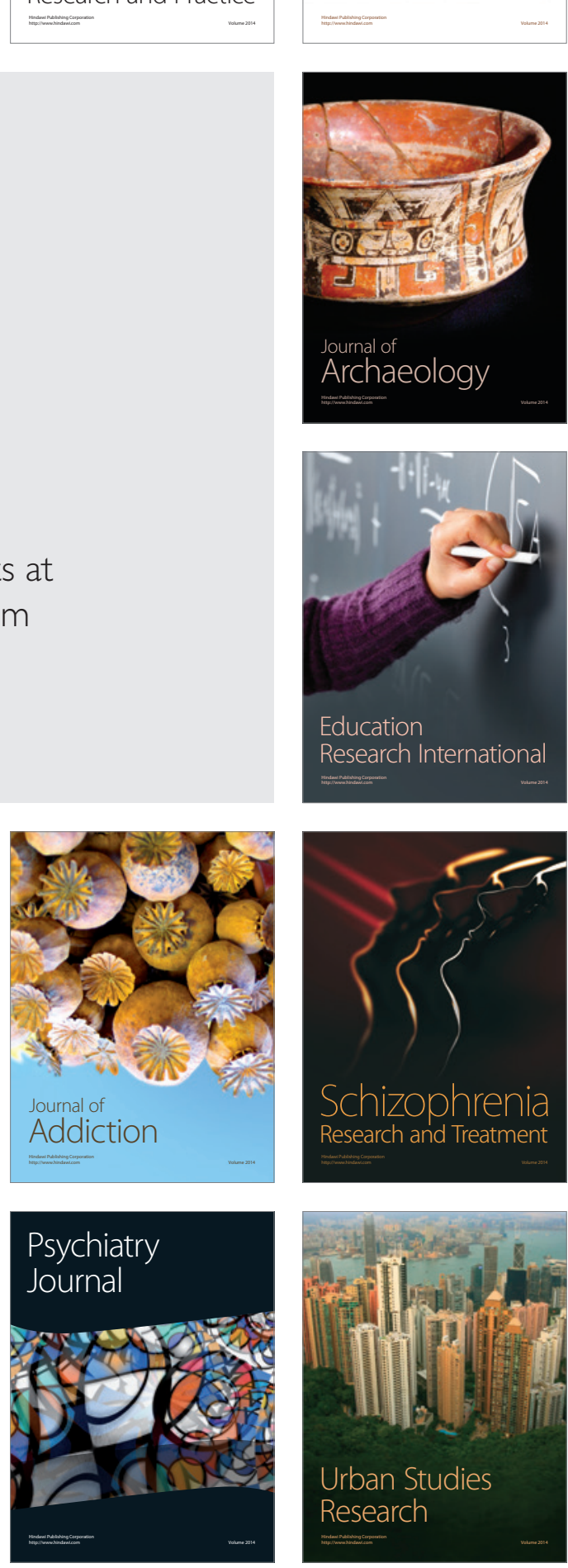